\title{
Comparative Study of Performance of CMIP3 GCMs in Simulating the East Asian Monsoon Variability
}

\author{
Sahana Paul and Huang-Hsiung Hsu * \\ Department of Atmospheric Sciences, National Taiwan University, Taipei, Taiwan
}

Received 2 August 2011, accepted 1 February 2012

\begin{abstract}
This study evaluates variability of East Asian Monsoon simulated by 24 coupled general circulation models (GCMs) participating in Coupled Model Inter-comparison Project 3 (CMIP3). Fifty years (1950 - 1999) of each model's twentiethcentury climate simulation are analyzed and compared with observed data. Both East Asian Summer Monsoon (EASM) and East Asian Winter Monsoon (EAWM) are considered. Suitable indices are selected to analyze EASM and EAWM. The Wang-Fan index, associated with $850 \mathrm{hPa}$ circulation pattern and tripole rainfall pattern are considered to analyze EASM. ICHENW, associated with $850 \mathrm{hPa}$ circulation pattern, IGONGDY, associated with Siberian High, and ISUNBM, associated with $500 \mathrm{hPa}$ East Asian trough are considered for analysis of EAWM. Inter-decadal and inter-annual variability of the EASM and EAWM are major focus of this study.

The results indicate that, amplitude of inter-annual component EASM becomes larger after 1980's. The decadal component shows, weakening trend and switching from positive monsoon phase to negative monsoon phase in mid-80s for both EASM and EAWM. The simulated composite differences between weak and strong monsoon decades by models with above mentioned characteristics are compared with observation for further evaluation. The EASM weakening is associated with weaker southwesterly and stronger anti-cyclonic pattern over Western North Pacific and results in more rainfall in south and north China, Korea, Japan and less rainfall in central China. The EAWM weakening is associated with weakening of Siberian High and temperature rise over East Asia. EASM and EAWM matrices are constructed according to the relative merits of GCMs.
\end{abstract}

Key words: East Asian monsoon, Monsoon index, Tripole pattern

Citation: Paul, S. and H. H. Hsu, 2012: Comparative study of performance of CMIP3 GCMs in simulating the East Asian monsoon variability. Terr. Atmos. Ocean. Sci., 23, 377-395, doi: 10.3319/TAO.2012.02.01.01(A)

\section{INTRODUCTION}

In preparation for the Intergovernmental Panel on Climate Change (IPCC) Fourth Assessment Report (AR4), more than a dozen international climate modeling centers have conducted a comprehensive set of long-term simulations of climate during the twentieth century and various climate scenarios in the twenty-first century (IPCC 2007) under the coordination of the Coupled Model Inter-comparison Project 3 (CMIP3). As the need for research on climate change has grown and with the advances in computing power, GCMs have become more and more complex. Because of their complexity, they often lead to greater uncertainty

\footnotetext{
* Corresponding author

E-mail:hsu@webmail2.as.ntu.edu.tw
}

than desired (Raick et al. 2006). One of the primary factors related to uncertainty in CGMs is that different models can simulate quite different regional changes under the same anthropogenic forcings (Whetton et al. 1995; Kittel et al. 1998; Giorgi and Francisco 2000) and it is difficult to ascertain which GCMs are most reliable. Often, projections from GCMs are characterized by a low level of confidence and high level of uncertainty (Giorgi and Francisco 2000; Visser et al. 2000). Furthermore, previous studies have shown that there can be considerable differences in the accuracy of predictions from different models (Lorenz 1982; Delworth and Knutson 2000). It is difficult to identify the most suitable model simulations because of the varying performance of AOGCMs (Atmosphere Ocean Coupled General Circulation Model). CMIP3 has released 24 state-of-art GCMs 
from institutes all over the world and it is a common practice to project future climate based on the results of CMIP3 GCMs. Before projecting future changes in climate, evaluating these models is important.

Several studies have considered the validation of CMIP3 models in simulating the East Asian monsoon. Different models appear to be successful in simulating various characteristics of the East Asian monsoon. According to Annamalai et al. (2007) the ENSO-monsoon relationship was most accurately simulated by GFDL-CM2.0, GFDLCM2.1, MRI-CGCM2.3.2, ECHAM5/MPI-OM. Lin et al. (2006) reported that tropical intra-seasonal variability, especially the MJO precipitation variance was realistically simulated by only two models (ECHAM5/MPI-OM and CNRM-CM3) out of 14 CMIP3 GCMs. Additionally, the sub-seasonal variability of summer monsoon rainfall was realistically simulated by MIROC3.2(medres), ECHAM5/ MPI-OM, and CNRM-CM3 (Lin et al. 2008). On the other hand, average monthly summer rainfall was accurately simulated by CGCM3.1, INM-CM3.0, and MIROC3.2(hires), ECHAM5/MPI-OM, PCM (Kripalani et al. 2007). The onset and withdrawal of East Asia summer rainy season, an important aspect of the summer monsoon, was realistically simulated by CGCM 3.1 (T47 and T63), GFDL-CM2.1, 2.0, ECHAM5-MPI-OM, MRI-CGCM2.3.2 (Kitoh and Uchiyama 2006). For the case of surface air temperatures in China, most models show moderate results (Zhou and Yu 2006).

The year-to-year variation in the Asian monsoon is one of the most important signals of Earth's climate variability. How to best simulate and predict annual variation in the East Asian Monsoon is an important task in climate prediction. In order to quantify the variability in the East Asian monsoon, using a representative variable (or variables) as an objective measure (or measures) is one approach (Sun and Li 1997; Wang and Fan 1999; Chen et al. 2000; Gong et al. 2001). Using concise and meaningful indices to characterize monsoon variability can facilitate empirical studies on the relationship between monsoon variability and lower boundary forcing (Wang et al. 2008b; Wang and Chen 2010). In order to project the future characteristics of the East Asian monsoon, it is necessary to validate the capability of CMIP3 GCMs in quantifying the variability in the East Asian monsoon. This issue has been relatively unexplored in previous studies. The present study includes a comprehensive assessment of the relative merits of CMIP3 models in simulating the East Asian summer and winter monsoon (EASM and EAWM) variability. A large number of summer and winter monsoon indices have been proposed. Some of these indices are adopted in this study for model validation.

\section{DATA AND METHODOLOGY}

This study is based on the 20th century simulations (20C3M) of 24 GCMs provided by CMIP3, which is the main basis for the AR4 (IPCC 2007). Table 1 provides a list of 24 AOGCMs. Our analysis compares the performance of different GCM simulations in simulating the East Asian monsoon variability in the domain $0-50^{\circ} \mathrm{N}$ to $90-150^{\circ} \mathrm{E}$. The data used for evaluation are: (1) CRU TS 2.1 rainfall (Mitchell and Jones 2005), (2) Hadley Centre mean sea level pressure (Basnett and Parker 1997), and (3) the NCEP Reanalysis (Kalnay et al. 1996).

The performances of GCMs in simulating the interannual variability of the EASM and EAWM variability are evaluated using existing monsoon indices. A survey of previous studies indicated that there are at least 25 existing indices for the EASM (Wang et al. 2008a) and 18 indices for the EAWM (Wang and Chen 2010). Thus, it is difficult to select the most suitable indices for comparative studies.

The EASM is characterized by a complex spatial structure and temporal fluctuations that encompass both the tropics and the extra-tropics. An east-west elongated rain-belt is one of the prominent features of the EASM. The intense rains during summer in different regions and times are referred to by different names, such as Mei-yu in China, Baiu in Japan, and Changma in Korea. It is difficult to quantify the variability in the EASM with averaged rainfall over East Asia because of the large spatial and temporal variation. Therefore, most of the investigators searching for a simple index for the EASM strength use circulation parameters instead of rainfall (Webster and Yang 1992; Guo 1994; Wang and Fan 1999; Zhang et al. 2002). Wang et al. (2008a) analyzed all 25 indices for the EASM and recommended the Wang-Fan (WF) index as the most suitable (Wang and Fan 1999). Thus we used the WF index as one of our indices for the study of summer monsoon intensity over East Asia. The WF index is defined as the $\mathrm{U}_{850}$ in $5-15^{\circ} \mathrm{N}$ to $90-130^{\circ} \mathrm{E}$ minus $\mathrm{U}_{850}$ in $22.5-32.5^{\circ} \mathrm{N}$ to $110-140^{\circ} \mathrm{E}$, where $\mathrm{U}_{850}$ denotes the zonal wind at $850 \mathrm{hPa}$.

In contrast to the circulation, most studies characterize the rainfall variability in terms of the dominant spatial pattern, e.g., the leading EOF (Empirical Orthogonal Function). Hsu and Lin (2007) studied the tripole pattern, which is the leading EOF of rainfall at both inter-annual and decadal time scales in East Asia, and the associated circulation during the northern summer. The tripole pattern is closely associated with the wave-like Pacific Japan pattern, which is the most recurrent dominant circulation pattern associated with the EASM (Nitta 1987; Lau 1992; Nitta and Hu 1996). In this study we consider the tripole pattern as another index of the summer monsoon index. The following procedures were carried out to isolate the inter-annual variability of the tripole pattern. The linear trend at each grid point is derived using linear regression and then subtracted. We analyzed the inter-annual and decadal components. The 9-year running means were then computed and subtracted from the detrended data to exclude the decadal and interdecadal signals, retaining the inter-annual component. 
Table 1. CMIP3 GCMs in this study.

\begin{tabular}{|c|c|c|c|}
\hline No. & Model & CMIP3 I.D. & Resolution \\
\hline 1 & Bjerknes Centre for Climate Research & BCCR-BCM2.0 & $64 \times 128$ \\
\hline 2 & \multirow{2}{*}{ Canadian Center for Climate Modeling and Analysis, Canada } & CGCM3.1(T63) & $64 \times 128$ \\
\hline 3 & & CGCM3.1(T47) & $48 \times 96$ \\
\hline 4 & \multirow{2}{*}{$\begin{array}{l}\text { Australia's Commonwealth Scientific and Industrial Research } \\
\text { Organization, Australia }\end{array}$} & CSIRO-Mk3.0 & $96 \times 196$ \\
\hline 5 & & CSIRO-Mk3.5 & $96 \times 192$ \\
\hline 6 & \multirow{2}{*}{ Geophysical Fluid Dynamics Laboratory, USA } & GFDL-CM2.0 & $90 \times 144$ \\
\hline 7 & & GFDL-CM2.1 & $90 \times 144$ \\
\hline 8 & \multirow{3}{*}{ GISS, USA } & GISS-AOM & $60 \times 90$ \\
\hline 9 & & GISS-EH & $46 \times 72$ \\
\hline 10 & & GISS-ER & $46 \times 72$ \\
\hline 11 & Institute of Atmospheric Physics, China & FGOALS-g1.0 & $60 \times 148$ \\
\hline 12 & Institute for Numerical Mathematics, Russia & INM-CM3.0 & $45 \times 72$ \\
\hline 13 & National Institute of Geophysics and Volcanology, Bologna, Italy & INGV-SXG & $160 \times 320$ \\
\hline 14 & Institute Pierre Simon Laplace, France & IPSL-CM4 & $72 \times 96$ \\
\hline 15 & \multirow{2}{*}{ Institute Pierre Simon Laplace, France } & MIROC3.2(hires) & $160 \times 320$ \\
\hline 16 & & MIROC3.2(medres) & $64 \times 128$ \\
\hline 17 & $\begin{array}{l}\text { Meteorological Institute, University of Bonn, Germany } \\
\text { Meteorological Research Institute of KMA, Korea } \\
\text { Model and Data Group at MPI-M, Germany }\end{array}$ & ECHO-G & $48 \times 96$ \\
\hline 18 & Max-Planck-Institut for Meteorology, Germany & ECHAM5/MPI-OM & $96 \times 192$ \\
\hline 19 & Meteorological Research Institute, Japan & MRI-CGCM2.3.2 & $64 \times 128$ \\
\hline 20 & \multirow{2}{*}{ National Centre for Atmospheric Research, USA } & CCSM3 & $64 \times 128$ \\
\hline 21 & & PCM & $64 \times 128$ \\
\hline 22 & \multirow{2}{*}{ UK Met. Office, UK } & UKMO-HadCM3 & $73 \times 96$ \\
\hline 23 & & UKMO-HadGEM1 & $145 \times 192$ \\
\hline 24 & Centre National de Recherches Meteorologiques, France & CNRM-CM3 & $64 \times 128$ \\
\hline
\end{tabular}

Wang and Chen (2010) have elaborated the interpretation of the 18 existing EAWM indices and classified them into four categories: low level wind indices, upper zonal wind shear indices, east-west pressure contrast indices, and East Asian trough indices. According to their results, three indices described below are chosen for this study.

(1) ICHENW [average v wind component over East China Sea and South China Sea $\left(10-25^{\circ} \mathrm{N}, 110-130^{\circ} \mathrm{E}\right.$ and $\left.\left.25-40^{\circ} \mathrm{N}, 120-140^{\circ} \mathrm{E}\right)\right]$ [Chen et al. (2000)] for the northeasterly variability.

(2) IGONGDY [mean SLP over the centre of the Siberian High $\left(40-60^{\circ} \mathrm{N}, 70-120^{\circ} \mathrm{E}\right)$ ] [Gong et al. (2001)] for the Siberian High variability.

(3) ISUNBM [average Normalized 500 hpa Geo-potential Height over $\left(35-40^{\circ} \mathrm{N}, 125-145^{\circ} \mathrm{E}\right)$ ] [Sun and $\mathrm{Li}(1997)$ ] for the lower-tropospheric temperature variability.
The justification for selecting these indices is as follows. ICHENW is a circulation index which is related to the El Niño and Southern Oscillation (ENSO) and is suitable for looking at the tropical Pacific's influence on the EAWM. The monsoon index IGONGDY is related to the intensity of Siberian High and is therefore suitable for evaluating the effect of high latitudes on the EASM. The monsoon index ISUNBM represents the fluctuation of the $500 \mathrm{hPa}$ geo-potential height over East Asia, where cold air usually penetrates southward. The ISUNBM index is used in this study to reflect the fluctuation of air temperature in the lower troposphere along the East Asian coast.

The above indices are calculated based on the output from the GCMs and compared with the observed data to evaluate the ability of 24 GCMs in simulating the EAM climate variability. The time period analyzed for this study is 
from 1950 to 1999. Seasonal means are considered throughout this study. We use the means for June-July-August (JJA) for summer and December-January-February (DJF) for winter. The difference between strong decadal monsoon and weak decadal monsoon in the time series for the decadal component (9 years average mean) was compared between the GCM output and the observed data. We consider this a composite difference between a strong and weak monsoon period for different parameters (temperature, rainfall, wind speed etc.) which reflect the main features of EASM and EAWM. Strong and weak monsoon decades are identified when the normalized indices of the decadal component exceeded \pm .5 .

\section{SUMMER MONSOON VARIABILITY}

Here the simulated seasonal average (JJA) rainfall and variability for the last 50 years (1950 - 1999) extracted from the 20C3M simulations for each of the 24 models are compared and evaluated against the observed data. Many models simulated a reasonable spatial distribution. Correlation coefficients (pattern correlation) between the observed and simulated mean rainfall (Table 2, column 1) are above 0.6 for all but 5 GCMs (i.e., FGOALS-g1 .0, IPSL-CM4, MRICGCM2.3.2, PCM, and CNRM-CM3). However, a high correlation does not necessarily warrant a model's ability to simulate the major characteristics of the rainfall distribution. As seen in Fig. 1, the measured rainfall is characterized by a northwestward decrease from the coastal area to deep area in the continent, i.e., more rainfall in the Indochina peninsula, Philippines, southeastern China, Japan and Korea, and less rainfall in northwestern China. Ten [CSIRO, GFDL, GISSAOM, INGV-SXG, MIROC3.2(hires), UKMO, CNRMCM3] out of twenty four GCMs reasonably simulated this overall pattern. It is interesting to note that all of these GCMs have high spatial resolution. On the other hand,

Table 2. Summer monsoon matrix.

\begin{tabular}{|c|c|c|c|c|c|c|c|c|c|c|c|}
\hline & 1 & 2 & 3 & 4 & 5 & 6 & 7 & 8 & 9 & 10 & 11 \\
\hline BCCR-BCM2.0 & .56 & .58 & $\mathrm{Y}$ & - & - & - & - & $\mathrm{Y}$ & .45 & $\mathrm{~N}$ & - \\
\hline CGCM3.1(T63) & .58 & .41 & $\mathrm{Y}$ & .26 & $\mathrm{Y}$ & .63 & $\mathrm{Y}$ & $\mathrm{N}$ & - & $\mathrm{Y}$ & -.54 \\
\hline CGCM3.1(T47) & .59 & .34 & $\mathrm{Y}$ & .12 & $\mathrm{~N}$ & .35 & $\mathrm{Y}$ & $\mathrm{N}$ & - & $\mathrm{Y}$ & -.13 \\
\hline CSIRO-Mk3.0 & .72 & .73 & $\mathrm{Y}$ & .25 & Y & .77 & Y & $\mathrm{Y}$ & .12 & $\mathrm{Y}$ & -.56 \\
\hline CSIRO-Mk3.5 & .74 & .73 & $\mathrm{~N}$ & - & - & - & - & $\mathrm{Y}$ & -.41 & $\mathrm{Y}$ & .44 \\
\hline GFDL-CM2.0 & .63 & .48 & $\mathrm{~N}$ & - & - & - & - & $\mathrm{Y}$ & +.34 & $\mathrm{Y}$ & .45 \\
\hline GFDL-CM2.1 & .71 & .46 & $\mathrm{~N}$ & - & - & - & - & $\mathrm{Y}$ & .46 & $\mathrm{Y}$ & .59 \\
\hline GISS-AOM & .60 & .37 & $\mathrm{~N}$ & - & - & - & - & $\mathrm{Y}$ & .74 & $\mathrm{Y}$ & -.68 \\
\hline GISS-EH & .57 & .40 & $\mathrm{Y}$ & -.00 & $\mathrm{~N}$ & .18 & $\mathrm{Y}$ & $\mathrm{Y}$ & -.17 & $\mathrm{Y}$ & -.60 \\
\hline GISS-ER & .65 & .43 & $\mathrm{Y}$ & .14 & $\mathrm{~N}$ & .38 & $\mathrm{Y}$ & $\mathrm{N}$ & - & $\mathrm{Y}$ & -.15 \\
\hline FGOALS-g1.0 & .23 & .31 & $\mathrm{~N}$ & - & - & - & - & $\mathrm{Y}$ & -.46 & $\mathrm{Y}$ & -.75 \\
\hline INGV-SXG & .79 & .67 & $\mathrm{Y}$ & -.15 & $\mathrm{~N}$ & .62 & $\mathrm{Y}$ & $\mathrm{Y}$ & -.39 & $\mathrm{Y}$ & .62 \\
\hline INM-CM3.0 & .65 & .63 & $\mathrm{Y}$ & .02 & $\mathrm{~N}$ & .27 & $\mathrm{Y}$ & $\mathrm{N}$ & - & $\mathrm{Y}$ & .42 \\
\hline IPSL-CM4 & .50 & .54 & $\mathrm{Y}$ & - & - & - & - & $\mathrm{Y}$ & -.43 & $\mathrm{~N}$ & - \\
\hline MIROC3.2(hires) & .72 & .68 & $\mathrm{~N}$ & - & - & - & - & $\mathrm{Y}$ & -.53 & $\mathrm{Y}$ & .43 \\
\hline MIROC3.2(medres) & .75 & .67 & $\mathrm{Y}$ & -.05 & $\mathrm{~N}$ & .76 & $\mathrm{Y}$ & $\mathrm{Y}$ & -.59 & $\mathrm{Y}$ & -.42 \\
\hline ECHO-G & .71 & .65 & $\mathrm{~N}$ & - & - & - & - & $\mathrm{N}$ & - & $\mathrm{N}$ & - \\
\hline ECHAM5/MPI-OM & .57 & .52 & $\mathrm{~N}$ & - & - & - & - & $\mathrm{Y}$ & -.18 & $\mathrm{Y}$ & .04 \\
\hline MRI-CGCM2.3.2 & .44 & .43 & $\mathrm{Y}$ & .35 & $\mathrm{Y}$ & .84 & $\mathrm{Y}$ & $\mathrm{Y}$ & .28 & $\mathrm{Y}$ & -.30 \\
\hline CCSM3 & .68 & .64 & $\mathrm{Y}$ & .06 & $\mathrm{Y}$ & .39 & $\mathrm{Y}$ & $\mathrm{N}$ & - & $\mathrm{N}$ & - \\
\hline PCM & .35 & .38 & $\mathrm{~N}$ & - & - & - & - & $\mathrm{Y}$ & -.29 & $\mathrm{Y}$ & .59 \\
\hline UKMO-HadCM3 & .74 & .76 & $\mathrm{~N}$ & - & - & - & - & $\mathrm{Y}$ & -.78 & $\mathrm{Y}$ & .43 \\
\hline UKMO-HadGEM1 & .80 & .70 & $\mathrm{Y}$ & .08 & $\mathrm{Y}$ & .68 & $\mathrm{Y}$ & $\mathrm{Y}$ & -.60 & $\mathrm{Y}$ & .60 \\
\hline CNRM-CM3 & .44 & .45 & $\mathrm{~N}$ & - & - & - & - & $\mathrm{N}$ & - & $\mathrm{N}$ & - \\
\hline
\end{tabular}

Note:

$1=$ Correlation between observation and the GCMs for mean rainfall pattern; $2=$ Correlation between observation and the GCMs for rainfall variability pattern; $3=$ Showing weakening according to IWF*; $4=$ Spatial correlation between model observation according to IWF* for rainfall; 5 = Decrease of rainfall over Central China; 6 = Spatial correlation between model observation according to IWF $*$ for stream function; $7=$ Showing anti-cyclonic circulation over western north Pacific; $8=$ Tripole pattern of rainfall for decadal component; $9=$ Spatial correlation between observation and GCM; $10=$ Tripole pattern of rainfall for inter-annual component; 11 = Spatial correlation between observation and GCM.

*IWF= Wang-Fag Index. 

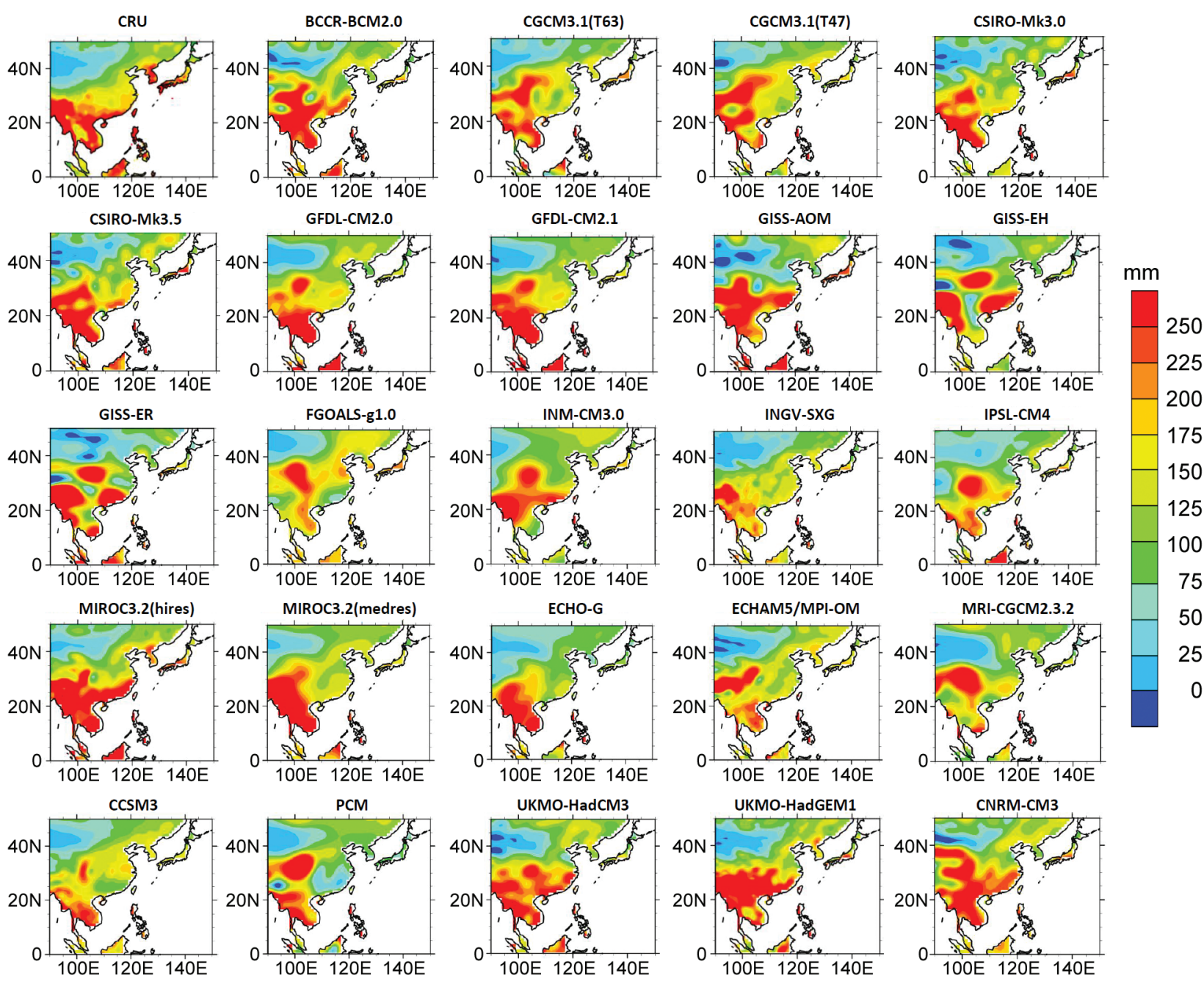

Fig. 1. Comparison of average summer rainfall for GCMs with observation during 1950 - 1999.

higher resolution does not guarantee better simulations. The ECHAM5/MPI-OM model with relatively high resolution is an example of this. Almost all GCMs simulated anomalously high rainfall in central China near Sichuan Basin where lee cyclogenesis is active. Whether these GCMs overestimated lee cyclogenesis in this region is a worthwhile focus for further investigation.

The simulated spatial distribution of inter-annual variation in rainfall is also examined. As shown in column 2 of Table 2 (figure not shown), the models did not accurately simulate the inter-annual variation. Eleven out of $24 \mathrm{GCMs}$ had correlation coefficients less than 0.6. A comparison between column 1 and 2 also reveals that the models that are simulating mean annual rainfall also provide better simulations of inter-annual variability.

The temporal/spatial performance and prediction potential for 1950 - 1999 for different GCMs are evaluated using the WF Index and the tripole pattern. The temporal variability in normalized inter-annual and decadal component of the WF index simulated by different GCMs and the observed data are compared in Fig. 2. The observed WF index (derived from NCEP reanalysis data) is dominated by inter-annual variability. The WF index also exhibits clear inter-decadal fluctuations characterized by the change from an upward trend to a downward trend around the late 1980s. This shift reflects a weakening trend of the EASM starting from 1980s, as pointed out in previous studies (Yu et al. 2004). It is also worth noting that the amplitude of the interannual variability appears larger after the late 1970s. Even though the $20 \mathrm{C} 3 \mathrm{M}$ simulations include precribed external forcings such as greenhouse gas aerosol concentration, and the solar constant, etc., atmospheric and oceanic variability are still affected by models' natural variability. Due to the stochastic nature of the forcings, the temporal fluctuation of the simulated EASM may differ markedly from the observed data even if the variability is essentially the same as the variation in the observed data in a statistical sense. It is therefore not meaningful to compare the simulated interannual and inter-decadal variation with the observed data in detail. On the other hand, it would be interesting to know if 


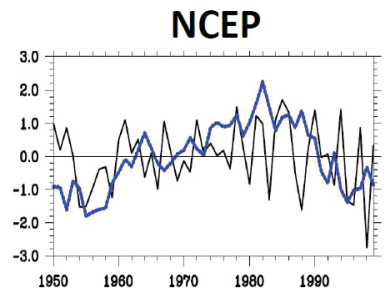

CSIRO-Mk3.0

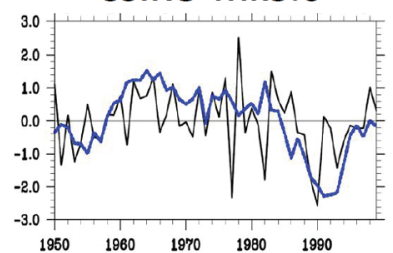

INGV-SXG

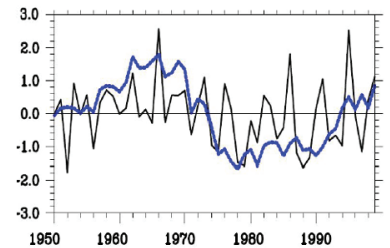

CCSM3

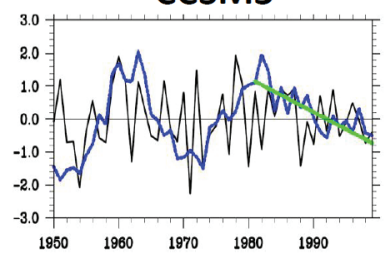

BCCR-BCM2.0

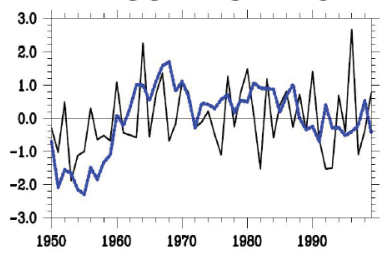

GISS-EH

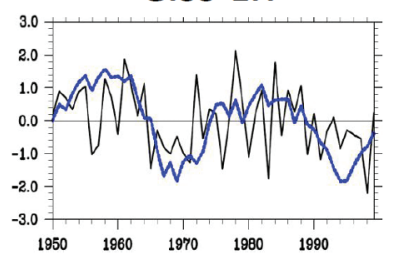

IPSL-CM4

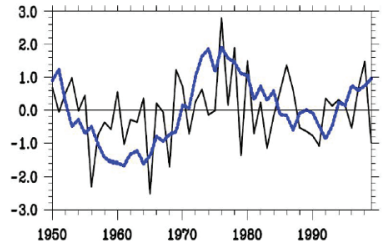

UKMO-HadGEM1

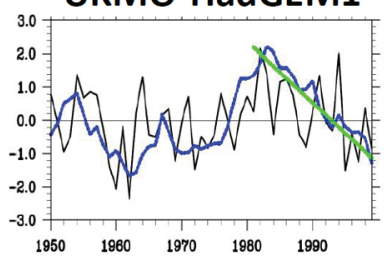

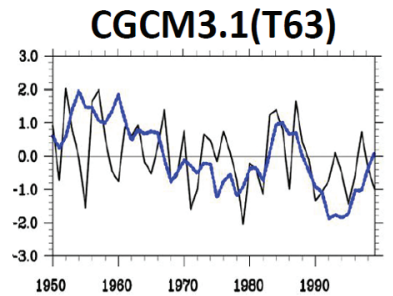

GISS-ER

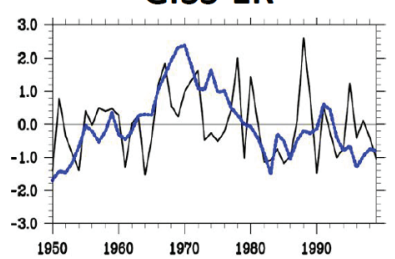

MIROC3.2(medres)

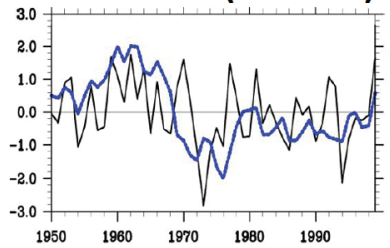

MRI-CGCM2.3.2

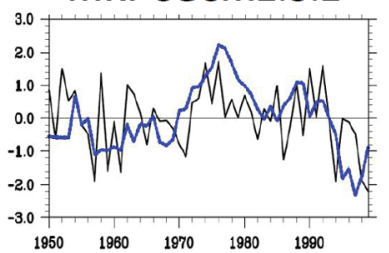

Fig. 2. Time series of monsoon index (IWF) of the GCMs showing weakening and observation (black line shows the inter-annual component and blue line shows the decadal component of monsoon index in each figure).

24 GCMs are capable of simulating the observed weakening EASM.

Despite this, it would be interesting to know whether the GCMs accurately simulate the contrasting rainfall and circulation characteristics between the strong and weak EASM. This study examined the 14 GCMs shown in Fig. 2 to search for one strong and one weak EASM decade. The selected decade for each model is presented in Table 3. Only those GCMs with the normalized anomaly in an entire decade larger than $( \pm) 0.5$ standard deviation are chosen. The selected decades for the NCEP are 1975 - 1984 and 1990 - 1999 for a strong and weak EASM. Because UKMOHadGEM1 and CCSM3 are the two GCMs whose selected decades best matched the observed data, we include them in the analysis even though the amplitude anomaly is relatively small. BCCR-BCM2.0 and IPSL-CM4 are the two GCMs excluded from further analysis because of small amplitudes.

The summertime circulation in East Asia and the Western North Pacific consists of three major components: thermal cyclonic circulation over land, the monsoon trough extending from the Eurasian continent to the Philippine Sea, and the Pacific subtropical anticyclonic ridge north of 
Table 3. Strong and weak monsoon decades for NCEP and the selected GCMs that shows weakening of summer monsoon according to IWF.

\begin{tabular}{lcc}
\hline GCM & $\begin{array}{c}\text { Strong monsoon } \\
\text { period (10 yrs) }\end{array}$ & $\begin{array}{c}\text { Weak monsoon } \\
\text { period (10 yrs) }\end{array}$ \\
\hline NCEP & $1975-1984(1.2)$ & $1990-1999(-.6)$ \\
BCCR-BCM2.0 & $1962-1971(.98)$ & $1990-1999(.21)$ \\
CGCM3.1(T63) & $1955-1964(1.12)$ & $1990-1999(-1.15)$ \\
CSIRO-Mk3.0 & $1960-1969(1.1)$ & $1985-1994(-1.5)$ \\
MIROC3.2(medres) & $1955-1964(1.3)$ & $1985-1994(-.65)$ \\
GISS-EH & $1952-1961(1.06)$ & $1990-1999(-1.04)$ \\
IPSL-CM4 & $1972-1981(1.2)$ & $1985-1994(0.23)$ \\
INGV-SXG & $1960-1969(1.3)$ & $1980-1989(-1.05)$ \\
MRI-CGCM2.3.2 & $1972-1981(1.3)$ & $1990-1999(-.76)$ \\
CGCM3.1(T47) & $1952-1961(1.1)$ & $1980-1989(-0.8)$ \\
GISS-ER & $1965-1974(1.3)$ & $1980-1989(-.53)$ \\
UKMO-HadGEM1 & $1978-1987(1.4)$ & $1990-1999(-.113)$ \\
INM-CM3.0 & $1950-1959(1.16)$ & $1975-1984(-.67)$ \\
CCSM3 & $1980-1989(.89)$ & $1990-1999(-.21)$ \\
\hline
\end{tabular}

the monsoon trough. The relative movement and amplitude variation of these three components have significant influence on the regional weather and climate. The WF index is designed to identify the strength of the monsoon trough. A larger (smaller) WF index indicates a stronger (weaker) monsoon trough and is interpreted as a strong (weak) EASM. A composite of the weak monsoon decades (i.e., later decades) are subtracted from a composite of strong monsoon decades (earlier decades) to examine the capability of the GCMs to simulate the observed contrasts between the strong and weak EASM. The composite difference of $850 \mathrm{hPa}$ wind field between the negative and positive phase monsoon decades (Fig. 3, upper left corner) shows a weaker westerly near the equator, which is the southern branch of an anticyclonic circulation anomaly covering the entire subtropical western North Pacific, and is accompanied by the northeasterly anomaly over Japan, the East China Sea, and eastern China. This means that during the latter decades when the monsoon is weak, the anomaly is anti-cyclonic and the monsoon trough is weaker when the anticyclone is stronger.

The corresponding rainfall anomaly shown in the upper left corner of Fig. 4 indicates a positive anomaly in southeastern China, northeastern Indochina peninsula, Korea, and northwestern China, and a negative anomaly in central
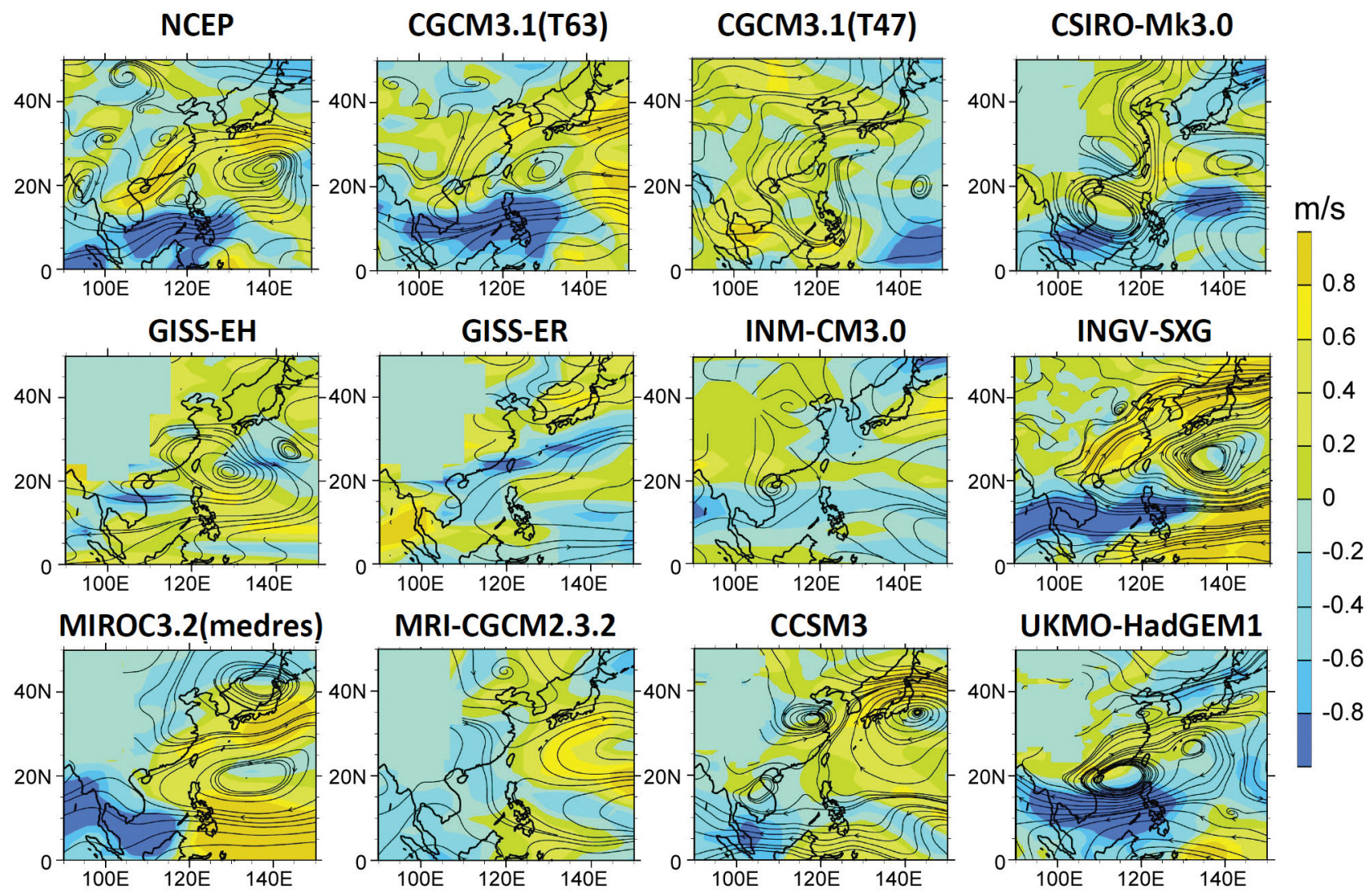

Fig. 3. Comparison of decadal difference between the negative and positive monsoon decades for wind field in between different GCMs and observation. 

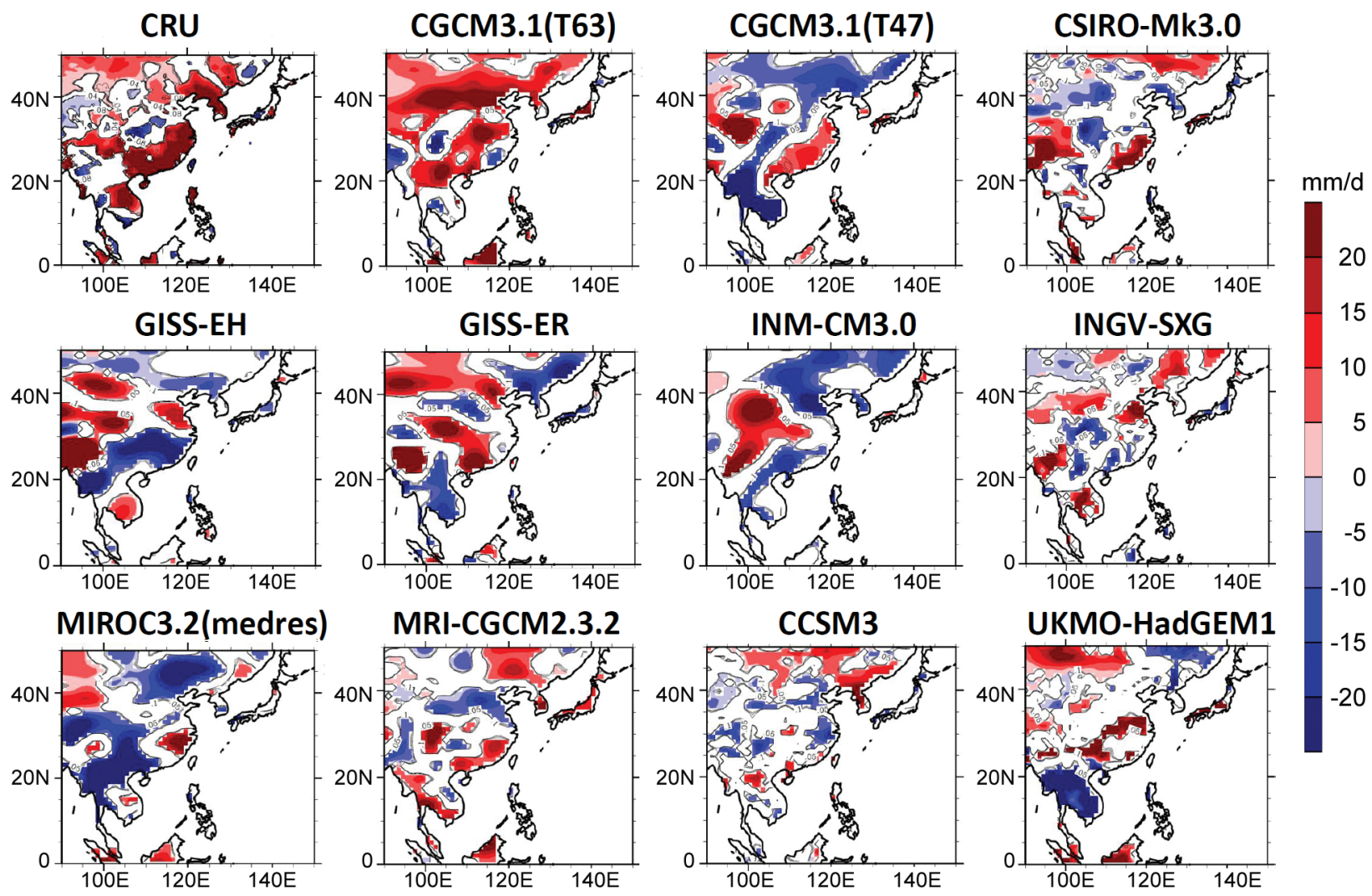

Fig. 4. Comparison of decadal difference between the negative and positive monsoon decades for precipitation in between different GCMs and observation.

China. The weaker monsoon trough is accompanied by stronger southwesterly flow to coastal East Asia. This circulation configuration would lead to more moisture transport and convergence, and therefore more rainfall in the area.

Simulated circulation and rainfall anomalies for the GCMs weakening of monsoon are shown in Figs. 3 and 4, and the corresponding pattern correlations are shown in columns 6 and 4 of Table 2, respectively. The stream function west of $120^{\circ} \mathrm{E}$ is not included in the computation of pattern correlation because of the lack of data in the mountainous area and the WF index is defined based on the circulation over ocean. Six GCMs [i.e., CGCM3.1(T63), CSIRO-Mk3 .0, INGV-SXG, MIROC3.2(medres), MRI-CGCM2.3.2, and UKMO-HadGEM1] reasonably simulate the circulation pattern with pattern correlation larger than 0.6. All of these six GCMs simulate an anticyclonic circulation somewhere in the Western North Pacific. However, the location of the anticyclonic circulation differs between GCMs. Qualitatively it can be seen that all the GCMs (Table 2, columns 6, 7) showing this weakening and can simulate an anti-cyclonic pattern somewhere over the western north Pacific although pattern correlation with observation may not be good.

The correlation for rainfall is much lower with only three GCMs exceeding 0.2 (Table 2, column 4). Qualitatively, the observed data show a negative rainfall anomaly (i.e., decrease of rainfall) over central China, which is reflected in some of the models, including CGCM3.1(T63), CSIRO-Mk3.0, MRI-CGCM2.3.2, CCSM3, UKMO-HadGEM1 (Table 2, column 5). It is interesting to note that the GCMs with the best correlation for rainfall are those models with the best performance in wind circulation simulation. On the other hand, GCMs that performed well in simulating wind circulation [e.g., INGV-SXG, MIROC3.2(medres), and UKMOHadGEM1] do not warrant a reasonable rainfall simulation. Also, none of the GCMs which simulate circulation poorly produce a reasonable simulation for rainfall. This indicates that the rainfall is so sensitive that a slight displacement of circulation results in a significantly different rainfall pattern. For example, the MIROC3.2(medres) model produces a circulation pattern correlation as high as 0.76 but with the correlation for rainfall is -.05 (Table 2, column 6). It is obvious by comparing Figs. 3 and 4 that the northward-displacement of the anticyclonic anomaly results in an easterly anomaly in southern China and negative rainfall anomaly in the northern Indochina Peninsula and southwestern China, instead of the southwesterly anomaly and positive rainfall anomaly as shown in the observed data. On the other hand, a seemingly good precipitation simulation does not necessarily result from a correct circulation pattern. An interesting example is MRI-CGCM2.3.2 that had correlations of 0.84 and 0.35 for 
stream function and rainfall, respectively. A close inspection reveals that the model simulated northerly anomaly, instead of southerly, over southeastern China. The northerly anomaly is part of the weak trough along the southeastern coast of China. The trough is evidently the cause for the positive rainfall anomaly. This indicates that a reasonable simulation of rainfall fluctuation is still a challenge for these GCMs even at decadal time scales.

As in previous studies and discussed above (Hsu and Lin 2007), the tripole pattern is a dominant pattern in both inter-annual and inter-decadal variability of EASM. Because it makes no sense to compare annual data, we evaluate the model performance in simulating the inter-decadal and as well as inter-annual variability by comparing the leading mode of the observed and simulated rainfall. The empirical orthogonal analysis is applied to the CRU data to retrieve the most recurrent pattern in East Asia. As noted before, both the trend and decadal fluctuations are removed before applying EOF to isolate the inter-annual variability. The first EOF of CRU data explains $23 \%$ of total variance and exhibits the well known tripole structure (Hsu and Lin 2007) with negative polarity over southern China, Taiwan, and northern China and positive polarity over central China, Japan, and Korea (Fig. 5). The positive and negative anomalies are elongated in the east-west direction and are relatively narrow in meridional direction. Corresponding time series show a distinct widening of amplitude of inter-annual variability in two recent decades, CSIRO-Mk3.0, CSIROMk3.5, GFDL-CM2.0, GFDL-CM2.1, GISS-AOM, GISSEH, INM-CM3.0, FGOALS-g1.0, INGV-SXG, MIROC3.2(hires), MIROC3.2(medres), PCM, UKMO-HadCM3, UKMO-HadGEM1 show a distinct tripole pattern in first or second EOF of their inter-annual variability with reasonably well spatial pattern correlation (Table 2, columns 10, 11). The corresponding time series are also presented in Fig. 5 for reference, although we do not expect the similarity to the observed time series. GISS-EH was the only one GCM showing the amplified amplitude after 1980s. Some models (e.g., BCCR-BCM2.0, IPSL-CM4, ECHO-G, CNRM-CM3) do not simulate any EOF similar to the tripole pattern.
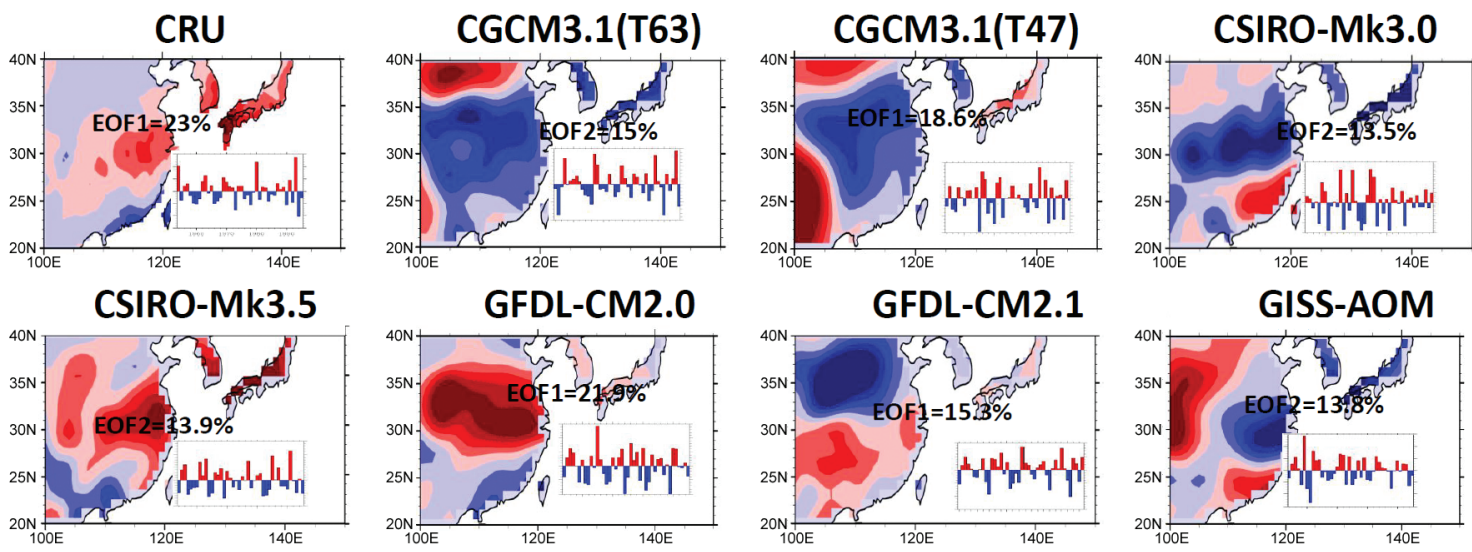

GFDL-CM2.1
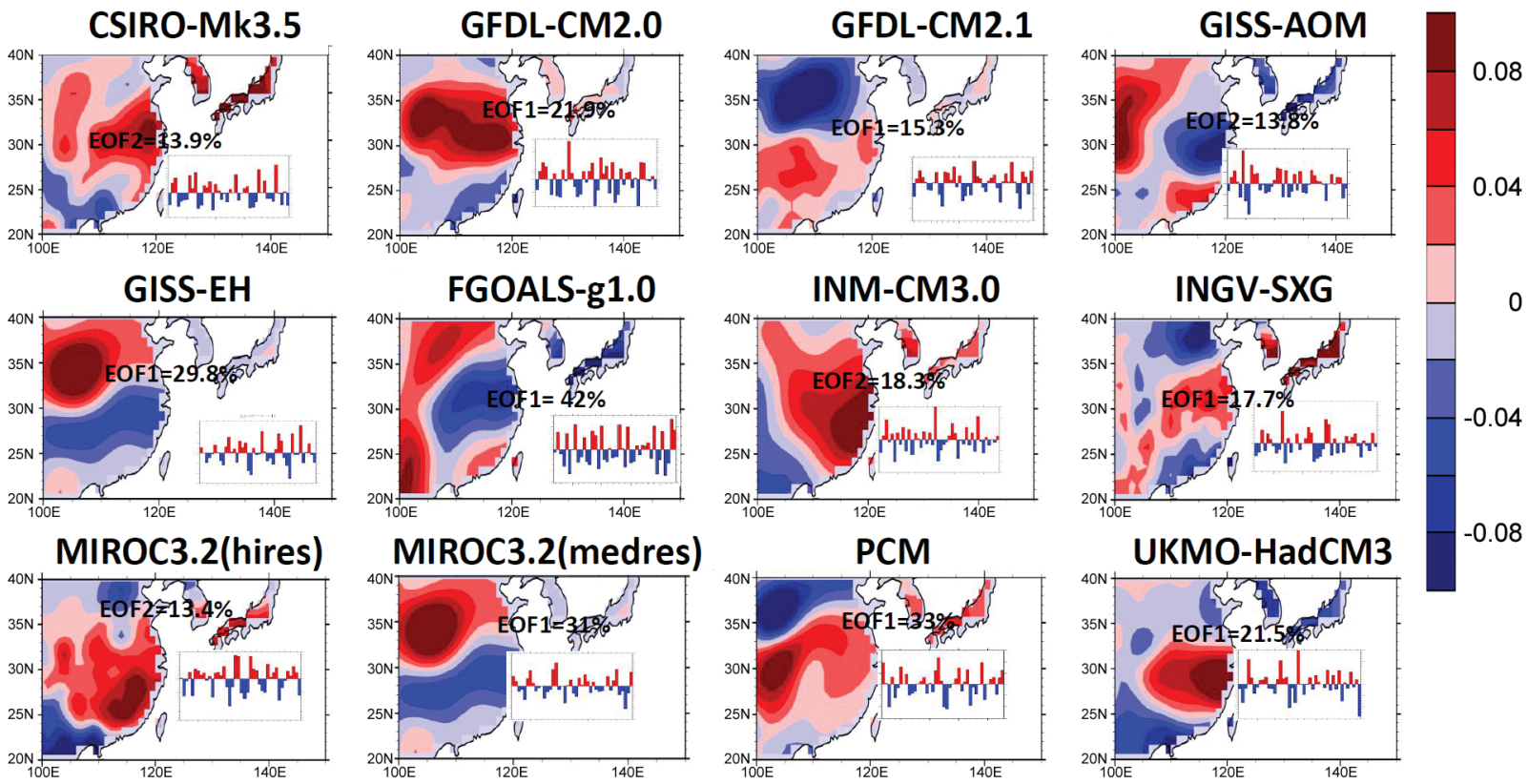

INM-CM3.0
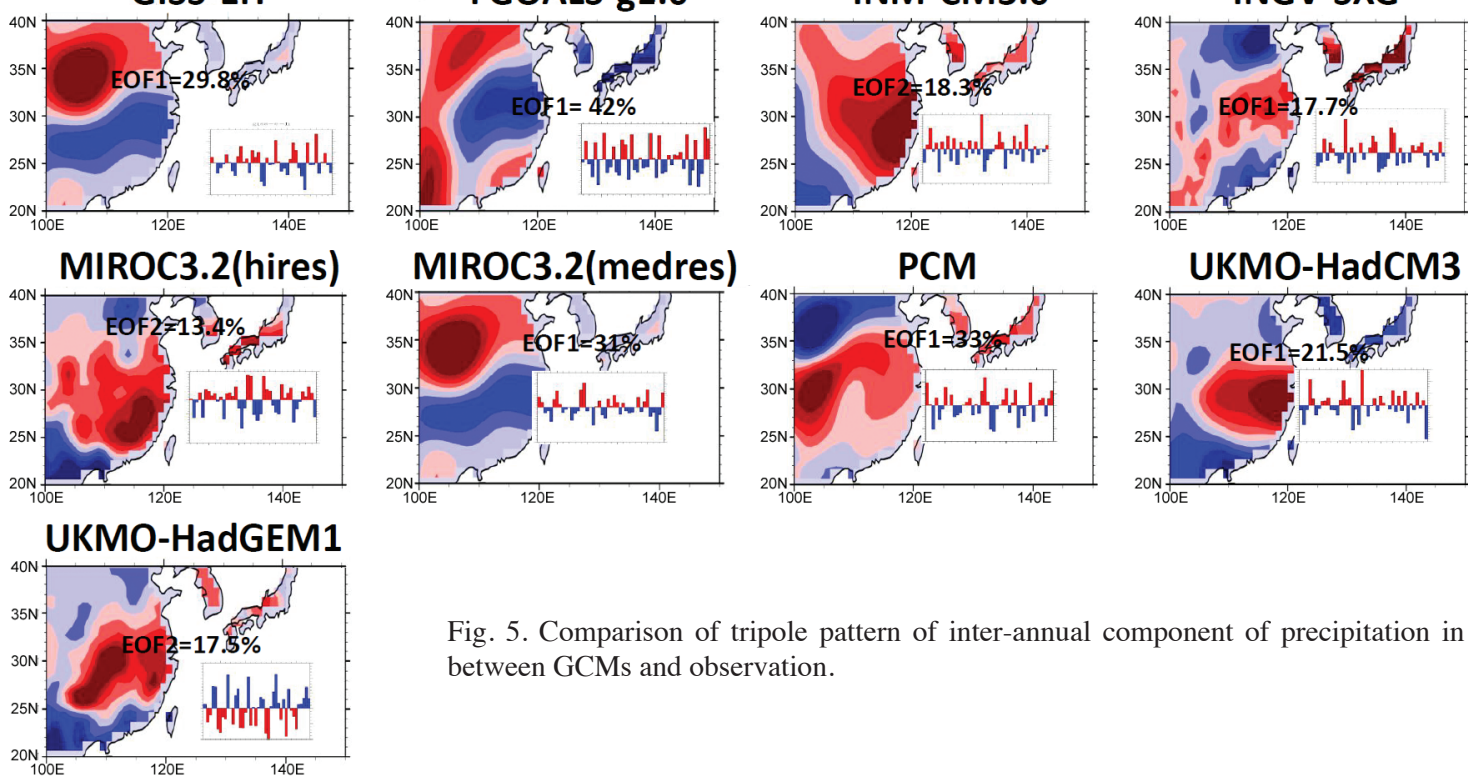

Fig. 5. Comparison of tripole pattern of inter-annual component of precipitation in between GCMs and observation. 
For the case of decadal component, CRU data explains the first EOF as the tripole pattern of rainfall with $22.2 \%$ of total variance (Fig. 6). The tripole pattern exhibits positive polarity over southern China, Taiwan, and northern China and negative polarity in central part of China, Japan, and Korea. The corresponding time series shows decadal variability with switching of phase in the late 1970s, indicating that northern and southern China become drier while central China became wetter after the late 1970s. Some models, including BCCR-BCM2.0, CSIRO-Mk3.5, GFDL-CM2.1, GISSAOM, FGOALS-g1.0, INGV-SXG, IPSL-CM4, MIROC3.2(hires), MIROC3.2(med), UKMO-HadCM3, UKMO-HadGEM1 show the tripole pattern in their decadal component with significant pattern correlation with the observed data (Table 2, columns 8,9). Although some models simulate the sign of switching, other models (e.g., BCCR-BCM2.0, FGOALS-g1.0, UKMO) indicate a drier central China after the phase change. MIROC3.2(medres) seems to be the only GCM simulated correct phase shift, although the timing does not seem correct. Thus the CMIP3 GCMs are capable of simulating the tripole pattern as leading EOFs but are not able to simulate the temporal characteristics.

\section{WINTER MONSOON VARIABILITY}

The East Asian winter monsoon directly influences the winter climate of East Asia. This is the most important circulation system of boreal winter over East Asia. The year to year variability of intensity of East Asian winter monsoon affects the wintertime temperature and rainfall variations over this region. Therefore, it is a necessity to quantify the strength of the East Asian winter monsoon and its variability. The simulated and observed seasonal average (DJF) temperature and MSLP climatology over East Asia are compared. All models reasonably simulate the average surface air temperature pattern during 1950 - 1999 and the correlations with the observed data are also very high (Table 4 , column 1). Besides, the simulated variability pattern of surface air temperature is also quite close to the observation. However, overestimates for the northern region result from some models such as INM-CM3.0, PCM, UKMO-HadGEM1, UKMO-HadCM3, GFDL-CM2.1, GFDL-CM2.0 (not shown). All of models perform well in case of mean MSLP pattern (Table 4, column 3). The MSLP variance pattern simulated by GCMs is close to the observations in most of the case except for GCMs GISS-AOM, GISS-EH, INMCM3.0, CCSM3.

Different investigators tried to define the large scale East Asian winter monsoon index with circulation parameters. Some of the distinct characteristics, like 500-hpa East Asian trough, east-west pressure contrast or subtropical surface meridional wind are used to define the East Asian winter monsoon strength (Guo 1994; Shi 1996; Sun and Li 1997; Cui and Sun 1999; Chen et al. 2000; Wang et al. 2009a). Thus far, 18 existing East Asian winter monsoon indices have been proposed and all are concerned with these
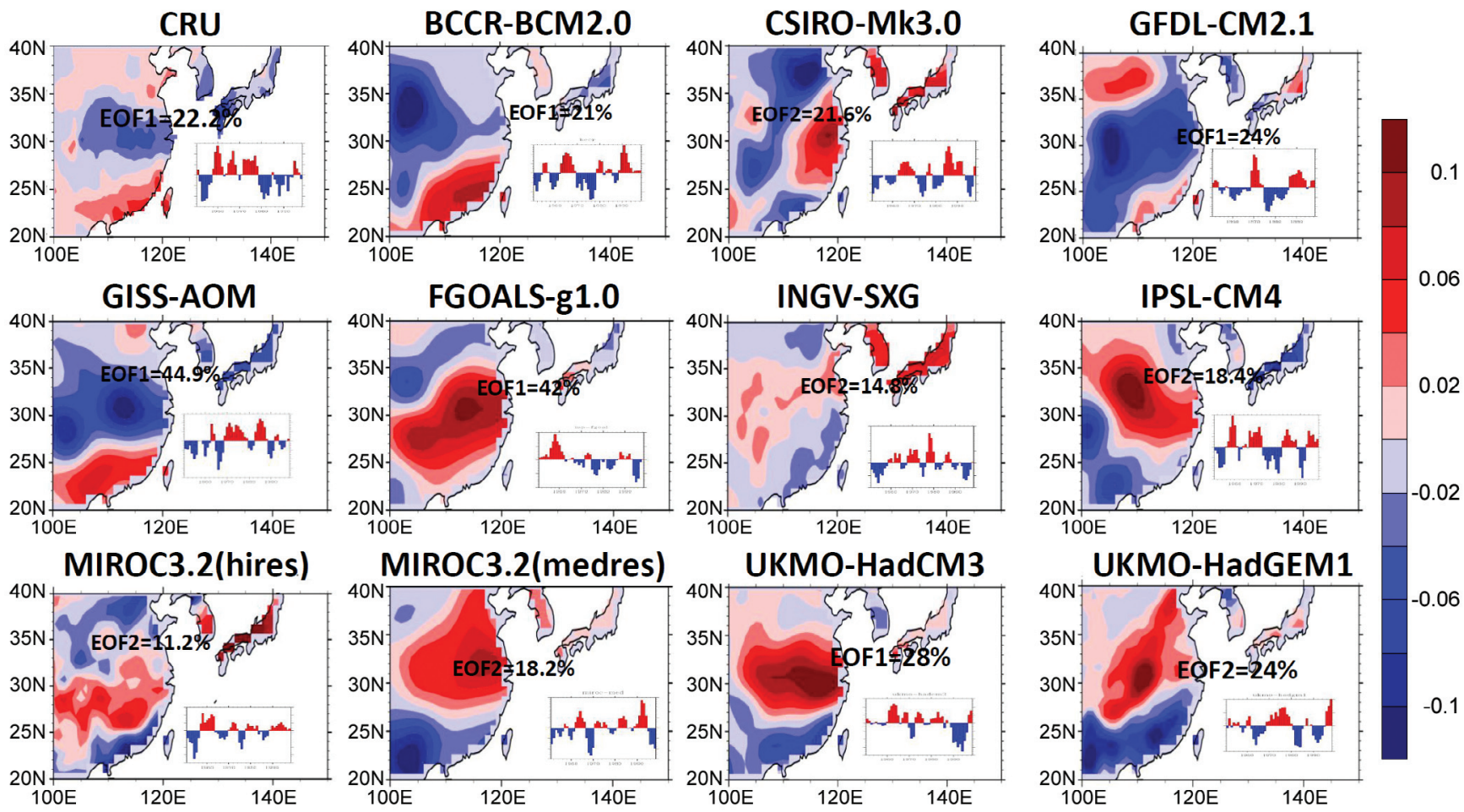

Fig. 6. Comparison of tripole pattern of decadal component of precipitation in between GCMs and observation. 
Table 4. Winter Monsoon Matrix.

\begin{tabular}{|c|c|c|c|c|c|c|c|c|c|c|c|c|c|c|c|c|c|c|c|c|c|}
\hline & 1 & 2 & 3 & 4 & 5 & 6 & 7 & 8 & 9 & 10 & 11 & 12 & 13 & 14 & 15 & 16 & 17 & 18 & 19 & 20 & 21 \\
\hline BCCR-BCM2.0 & .98 & .87 & .95 & .83 & Y & -.30 & -.48 & $\mathrm{~N}$ & -.19 & $\mathrm{~N}$ & $\mathrm{Y}$ & - & - & - & $\mathrm{Y}$ & .07 & $\mathrm{Y}$ & .35 & $\mathrm{~N}$ & .03 & $\mathrm{~N}$ \\
\hline CGCM3.1(T63) & .97 & .81 & .94 & .86 & Y & .45 & .42 & Y & .75 & Y & Y & .83 & .67 & $\mathrm{Y}$ & Y & - & - & - & - & - & - \\
\hline CGCM3.1(T47) & .96 & .82 & .94 & .84 & Y & .54 & .42 & $\mathrm{Y}$ & .60 & $\mathrm{Y}$ & $\mathrm{Y}$ & .69 & .21 & $\mathrm{~N}$ & $\mathrm{Y}$ & -.05 & $\mathrm{Y}$ & .35 & $\mathrm{~N}$ & -.07 & $\mathrm{~N}$ \\
\hline CSIRO-Mk3.0 & .98 & .83 & .91 & .78 & Y & .75 & -.36 & $\mathrm{~N}$ & .20 & $\mathrm{Y}$ & $\mathrm{Y}$ & .64 & .48 & $\mathrm{Y}$ & $\mathrm{N}$ & - & - & - & - & - & - \\
\hline CSIRO-Mk3.5 & .99 & .85 & .87 & .79 & $\mathrm{~N}$ & - & - & - & - & - & $\mathrm{N}$ & - & - & - & $\mathrm{N}$ & - & - & - & - & - & - \\
\hline GFDL-CM2.0 & .99 & .97 & .92 & .87 & $\mathrm{~N}$ & - & - & - & - & - & $\mathrm{N}$ & - & - & - & $\mathrm{N}$ & - & - & - & - & - & - \\
\hline GFDL-CM2.1 & .99 & .90 & .91 & .77 & $\mathrm{~N}$ & - & - & - & - & - & Y & .59 & .55 & Y & $\mathrm{N}$ & - & - & - & - & - & - \\
\hline GISS-AOM & .98 & .91 & .85 & .80 & Y & .71 & .55 & Y & .69 & $\mathrm{Y}$ & $\mathrm{Y}$ & .69 & .57 & $\mathrm{Y}$ & $\mathrm{Y}$ & .55 & $\mathrm{Y}$ & - & - & .33 & $\mathrm{Y}$ \\
\hline GISS-EH & .98 & .87 & .91 & .76 & $\mathrm{Y}$ & .43 & .02 & $\mathrm{~N}$ & -.20 & $\mathrm{~N}$ & $\mathrm{~N}$ & - & - & - & $\mathrm{N}$ & - & - & - & - & - & - \\
\hline GISS-ER & .97 & .89 & .92 & .78 & Y & .24 & -.08 & $\mathrm{~N}$ & .25 & $\mathrm{Y}$ & $\mathrm{Y}$ & .73 & .67 & Y & $\mathrm{Y}$ & .30 & $\mathrm{Y}$ & -.28 & $\mathrm{~N}$ & .23 & $\mathrm{Y}$ \\
\hline FGOALS-g1.0 & .98 & .83 & .95 & .83 & $\mathrm{~N}$ & - & - & - & - & - & $\mathrm{N}$ & - & - & - & $\mathrm{N}$ & - & - & - & - & - & - \\
\hline INGV-SXG & .98 & .89 & .94 & .86 & $\mathrm{Y}$ & .39 & .44 & Y & .64 & $\mathrm{Y}$ & $\mathrm{Y}$ & .50 & .29 & $\mathrm{Y}$ & $\mathrm{N}$ & - & - & - & - & - & - \\
\hline INM-CM3.0 & .96 & .84 & .84 & .77 & $\mathrm{Y}$ & .64 & .55 & $\mathrm{Y}$ & .65 & $\mathrm{Y}$ & $\mathrm{Y}$ & .68 & .55 & $\mathrm{Y}$ & $\mathrm{Y}$ & .66 & $\mathrm{Y}$ & .13 & $\mathrm{~N}$ & .41 & $\mathrm{Y}$ \\
\hline IPSL-CM4 & .98 & .82 & .78 & .82 & $\mathrm{Y}$ & .42 & .24 & $\mathrm{Y}$ & .41 & $\mathrm{Y}$ & $\mathrm{Y}$ & .61 & -.01 & $\mathrm{~N}$ & $\mathrm{Y}$ & -.10 & $\mathrm{~N}$ & .31 & Y & .58 & $\mathrm{Y}$ \\
\hline MIROC3.2(hires) & .99 & .86 & .86 & .84 & $\mathrm{Y}$ & -.51 & .15 & $\mathrm{~N}$ & .35 & $\mathrm{Y}$ & $\mathrm{Y}$ & .56 & -.11 & $\mathrm{~N}$ & $\mathrm{Y}$ & .36 & $\mathrm{~N}$ & -.01 & $\mathrm{Y}$ & .32 & $\mathrm{~N}$ \\
\hline MIROC3.2(medres) & .98 & .90 & .87 & .82 & $\mathrm{Y}$ & .58 & .70 & $\mathrm{Y}$ & .78 & $\mathrm{Y}$ & $\mathrm{Y}$ & .76 & .60 & $\mathrm{Y}$ & Y & .74 & $\mathrm{Y}$ & .05 & $\mathrm{Y}$ & .76 & $\mathrm{Y}$ \\
\hline ECHO-G & .98 & .84 & .93 & .79 & $\mathrm{~N}$ & - & - & - & - & - & $\mathrm{Y}$ & .73 & -.61 & $\mathrm{~N}$ & $\mathrm{Y}$ & .40 & $\mathrm{~N}$ & - & - & -.69 & $\mathrm{~N}$ \\
\hline ECHAM5/MPI-OM & .99 & .83 & .95 & .76 & $\mathrm{Y}$ & .24 & -.39 & $\mathrm{~N}$ & -.36 & $\mathrm{~N}$ & $\mathrm{~N}$ & - & - & - & $\mathrm{Y}$ & - & - & - & - & - & - \\
\hline MRI-CGCM2.3.2 & .98 & .80 & .89 & .86 & $\mathrm{Y}$ & .53 & .24 & Y & .57 & Y & $\mathrm{Y}$ & .75 & .42 & $\mathrm{Y}$ & $\mathrm{N}$ & - & - & - & - & - & - \\
\hline CCSM3 & .99 & .92 & .89 & .86 & $\mathrm{~N}$ & - & - & - & - & - & $\mathrm{N}$ & - & - & - & $\mathrm{N}$ & - & - & - & - & - & - \\
\hline PCM & .98 & .88 & .90 & .82 & $\mathrm{Y}$ & .77 & .49 & Y & .65 & $\mathrm{Y}$ & $\mathrm{Y}$ & - & - & - & $\mathrm{Y}$ & .23 & $\mathrm{Y}$ & -.44 & Y & .19 & $\mathrm{~N}$ \\
\hline UKMO-HadCM3 & .98 & .79 & .90 & .79 & Y & .51 & -.12 & $\mathrm{~N}$ & .17 & $\mathrm{Y}$ & $\mathrm{Y}$ & .39 & .24 & $\mathrm{~N}$ & $\mathrm{Y}$ & .23 & $\mathrm{Y}$ & .63 & $\mathrm{Y}$ & .31 & $\mathrm{Y}$ \\
\hline UKMO-HadGEM1 & .98 & .77 & .95 & .89 & $\mathrm{Y}$ & .61 & .52 & Y & .78 & $\mathrm{Y}$ & $\mathrm{Y}$ & .70 & .51 & $\mathrm{Y}$ & $\mathrm{N}$ & - & - & - & - & - & - \\
\hline CNRM-CM3 & .98 & .84 & .90 & .89 & Y & .28 & .41 & Y & .52 & $\mathrm{Y}$ & $\mathrm{Y}$ & .70 & .61 & $\mathrm{Y}$ & $\mathrm{Y}$ & .53 & Y & .50 & Y & .71 & $\mathrm{Y}$ \\
\hline
\end{tabular}

Note:

$1=$ spatial correlation of average temperature $; 2=$ spatial correlation of temperature variability; $3=$ spatial correlation of average MSLP $; 4=$ spatial correlation of MSLP variability; 5 = showing weakening according to ISUNBM; 6 = spatial correlation between model observation according to ISUNBM for geopotential height; 7 = spatial correlation between model observation according to ISUNBM for temperature; $8=$ rise of temperature ISUNBM; $9=$ spatial correlation between model observation according to ISUNBM for MSLP; $10=$ weakening of Siberian High; $11=$ showing weakening according to IGONGDY; 12 = spatial correlation between model observation according to IGONGDY for MSLP; 13 = spatial correlation between model observation according to IGONGDY for temperature; 14 = rise of temperature over north EA according to IGONGDY; 15 = showing weakening according to ICHENW; 16 = spatial correlation between model observation according to ICHENW for temperature; 17 = rise of temperature ICHENW; $18=$ spatial correlation between GCMs and observations according to ICHENW for strmline; $19=$ showing less north-easterly flow; $20=$ spatial correlation between model observation according to ICHENW for MSLP; 21 = weakening of Siberian High.

characteristics. Three indices, suggested by Wang and Chen (2010) namely ICHENW (Chen et al. 2000), IGONGDY (Gong et al. 2001), and ISUNBM (Sun and Lin 1997) are considered here. These indices are considered to produce skillful simulations of annual variation in the EAWM (Wang and Chen 2010).

We also compared temporal variability in the East Asian winter monsoon between the GCMs and the observations, as for the summer monsoon. The computed time series of ISUNBM for the observed and GCM data show strong inter-annual variability (Fig. 7). The positive (negative) index corresponds to positive (negative) phase of winter monsoon. The 9-year running mean produces the inter-decadal component which exhibits a continuous weakening trend
1970 onwards and a clear switching from positive monsoon phase to negative monsoon phase in mid-1980s (Fig. 7). This continuous weakening in decadal time scale and associated warming over East Asia is an important characteristic of EAWM (Chang et al. 2006; Wang et al. 2009b). Therefore, it is very important to evaluate GCMs in this respect. The decadal component of most of the GCMs like GISSAOM, INM-CM3.0, IPSL-CM4, MRI-CGCM2.3.2, PCM, UKMO-HadCM3, UKMO-HadGEM1, MIROC3.2(hires), MIROC3.2(medres), CNRM-CM3, BCCR-BCM2.0, CGCM3.1(T47), CGCM3.1(T63), GISS-ER, CSIRO-Mk3.0, GISS-EH, INGV-SXG, ECHAM5/MPI-OM exhibit the weakening. But among these GCMs, GISS-EH, INGVSXG, MIROC3.2(medres) fail to catch the continuous 


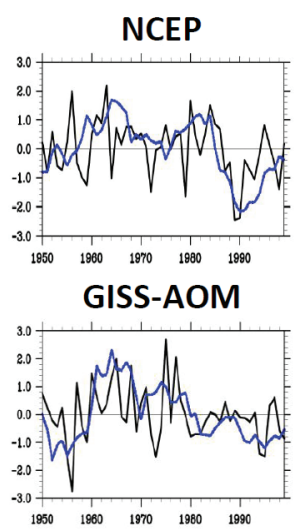

IPSL-CM4

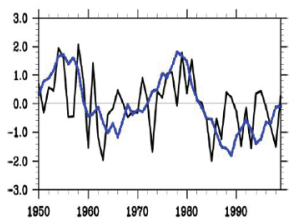

PCM

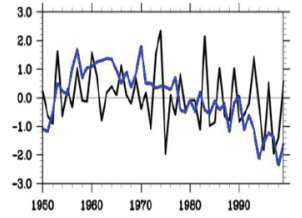

BCCR-BCM2.0

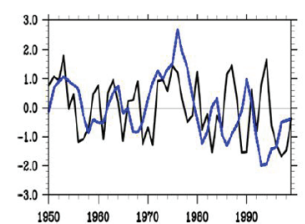

GISS-EH

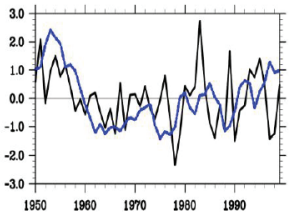

MIROC3.2(hires)

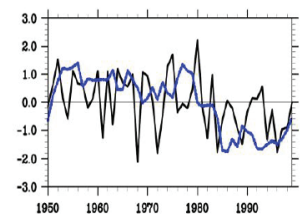

UKMO-HadCM3

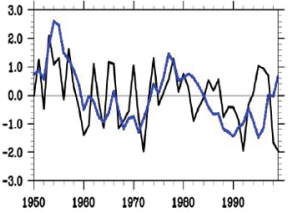

CGCM3.1(T63)

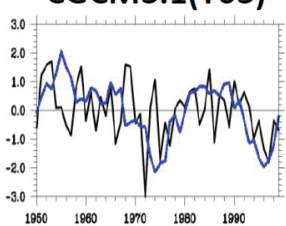

GISS-ER
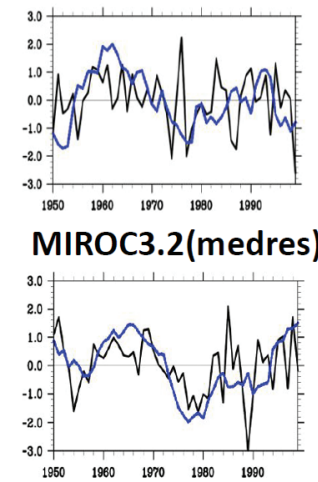

UKMO-HadGEM1

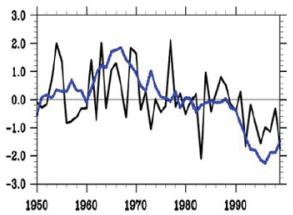

CGCM3.1(T47)

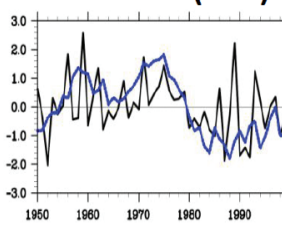

INM-CM3.0

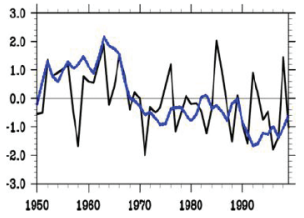

ECHAM5/MPI-OM

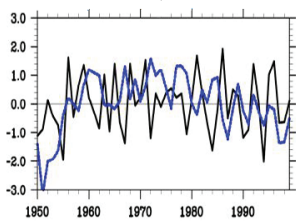

CNRM-CM3

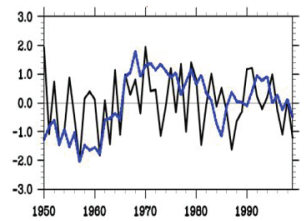

CSIRO-Mk3.0

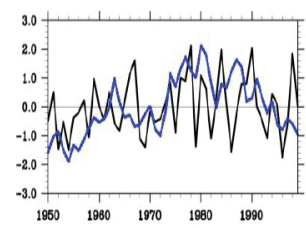

INGV-SXG

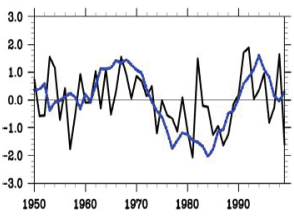

MRI-CGCM2.3.2

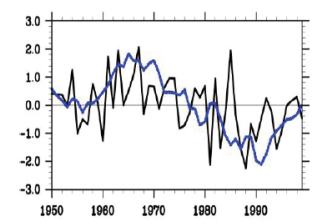

$1950 \quad 1960 \quad 1970 \quad 1930 \quad 1900$

Fig. 7. Time Series of ISUNBM of GCMs showing weakening of EAWM and Observation(black line shows the inter-annual component and blue line shows the decadal component of monsoon index in each figure).

weakening as indicated by the strengthening of monsoon in the late 1990s. The transition time, i.e., the time for switching of phase, varies for different GCMs compare to observation. The positive and negative monsoon decades are identified by decadal average of the decadal component of monsoon index more than \pm .5 (Table 5). Although CSIROMk3.0 and CNRM do not satisfy this criteria, but still they are considered due to continuously weakening since 1960 s for CNRM, and a sharp weakening in recent two decades for CSIRO-MK3.5. The anomalies related to the EAWM are illustrated by means of composite difference between positive and negative monsoon decades. A negative phase of the EAWM for the observed data revealed by ISUNBM is characterized by an increase of $500 \mathrm{hPa}$ geopotential heights over East Asia (Fig. 8), indicating an overall warming below $500 \mathrm{hPa}$ in the region. This feature is reasonably simulated by INM-CM3 .0, MRI-CGCM2.3.2, UKMO-HadGEM1, MIROC3.2(medres), GISS-AOM, CSIRO-Mk3.0, CGCM3.1 and all of them are highly correlated with the observation (Table 4, column 6). According to the observations, this characteristic is associated with weaker Siberian High and significant rise of temperature over the north and east and costal area of China, Korea, Japan, Taiwan. GCMs like CGCM3.1(T63), CGCM3.1(T47), GISS-AOM, INGV-SXG, INM-CM3.0, MIROC3.2(medres), UKMO-
HadGEM1, MRI-CGCM2.3.2, PCM can simulate this temperature increase very well (Fig. 9; Table 4, column 8), and the spatial correlation coefficients with the observation are also reasonably high for most of the GCMs (Table 4, column 7).

Similar types of study are performed using the index IGONGDY, which is associated with the intensity of Siberian High. The continuous weakening in decadal scale after 1970s is a distinctive feature of East Asian Winter Monsoon. This is pronounced in the observed data and some of the GCM simulations like CGCM3.1(T63), CGCM3.1(T47), GISS-AOM, GISS-ER, IPSL-CM4, ECHO-G, PCM, CNRM-CM3 (Fig. 10), although the transition time as well as the chosen positive and negative monsoon decades according to the above mentioned criteria imposed are not the same for the GCMs and the observations (Table 5). The negative phase of winter monsoon is characterized by weakening of Siberian High exhibited by the composite difference of mean sea level pressure between the weak and strong winter monsoon for observation (Fig. 11, upper left corner). Significant weakening of the Siberian High over the northern area of the domain as well as high pressure system over China are evident (Fig. 11), and are correlated with the GCM (we considered only GCMs with pronounced weak/strong decades according to our assumption) 
Table 5. Strong and weak monsoon decades for NCEP and the GCMs showing weakening according to EAWM indices.

\begin{tabular}{|c|c|c|c|c|c|c|}
\hline & \multicolumn{2}{|c|}{ ISUNBM } & \multicolumn{2}{|c|}{ IGONGDY } & \multicolumn{2}{|c|}{ ICHENW } \\
\hline & positive & negative & positive & Negative & positive & negative \\
\hline NCEP & $19760-1969(.9)$ & $1990-1999(-1.2)$ & $1962-1971(.68)$ & $1990-1999(-1.4)$ & $1968-1977(.58)$ & $1990-1999(-.8)$ \\
\hline GISS-AOM & $1962-1971(1.2)$ & $1990-1999(-.8)$ & $1960-1969(1.2)$ & $1990-1999(-1.2)$ & $1970-1979(.9)$ & $1990-1999(-1.4)$ \\
\hline INM-CM3.0 & $1955-1964(1.3)$ & $1990-1999(-1.1)$ & $1955-1964(1.5)$ & $1980-1989(-.9)$ & $1955-1964(1.5)$ & $1972-1981(.9)$ \\
\hline IPSL-CM4 & $1975-1984(.8)$ & $1985-1994(-1.1)$ & $1965-1974(1.5)$ & $1985-1994(-1.3)$ & $1965-1974(1.4)$ & $1985-1994(-1.3)$ \\
\hline MRI-CGCM2.3.2 & $1960-1969(1.1)$ & $1985-1994(-.5)$ & $1968-1977(.9)$ & & & \\
\hline PCM & $1960-1961(.9)$ & $1990-1999(-1.3)$ & $1955-1964(1.1)$ & $1990-1999(-.4)$ & $1960-1969(1.3)$ & $1980-1989(-.64)$ \\
\hline UKMO-HadCM3 & $1950-1959(1.3)$ & $1985-1994(-.9)$ & $1950-1959(.89)$ & $1990-1989(-.5)$ & $1980-1989(.9)$ & $1990-1999(-.6)$ \\
\hline UKMO-HadGEM1 & $1964-1973(1.2)$ & $1990-1999(-1.5)$ & $1962-1971(.73)$ & $1972-1981(-.8)$ & & \\
\hline MIROC3.2(hires) & $1952-1961(.9)$ & $1990-1999(-1.2)$ & $1958-1967(1.1)$ & $1975-1984(.5)$ & $1955-1964$ (.6) & $1985-1994(-.7)$ \\
\hline CNRM-CM3 & $1966-1975(1.1)$ & $1980-1989(.04)$ & $1955-1964(1.4)$ & $1980-1989(-.9)$ & $1964-1973(1.5)$ & $1990-1999(-.7)$ \\
\hline BCCR-BCM2.0 & $1970-1979(1.2)$ & $1990-1999(-.8)$ & & & $1980-1989(.9)$ & $1990-1999(-.4)$ \\
\hline CGCM3.1(T47) & $1966-1975(.5)$ & $1990-1999(-.8)$ & $1960-1969(1.2)$ & $1990-1999(-.7)$ & $1980-1989(1.0)$ & $1990-1999(-.9)$ \\
\hline CGCM3.1(T63) & $1950-1959(.8)$ & $1990-1999(-.8)$ & $1980-1989(.9)$ & $1990-1999(-1.1)$ & $1980-1989(1.1)$ & $1990-1999(.4)$ \\
\hline GISS-EH & $1950-1959(1.4)$ & $1960-1969(-.9)$ & & & & \\
\hline INGV-SXG & $1960-1969(.9)$ & $1975-1984(-1.4)$ & & & & \\
\hline MIROC3.2(medres) & $1960-1969(1.1)$ & $1975-1984(-1.3)$ & $1958-1967(1.3)$ & $1970-1979(-1.3)$ & $1960-1969(.7)$ & $1972-1981(-1.2)$ \\
\hline ECHAM5/MPI-OM & $1970-1979(.8)$ & $1990-1999(-.5)$ & & & $1970-1979(1.0)$ & $1990-1999(.52)$ \\
\hline CSIRO-Mk3.0 & $1975-1984(1.1)$ & $1990-1999(-.2)$ & & & & \\
\hline ECHO-G & & & $1970-1979(1.1)$ & $1990-1999(-1.3)$ & $1950-1959(1.3)$ & $1970-1979(-.86)$ \\
\hline GISS-ER & $1960-1969(1.2)$ & $1972-1981(-.7)$ & $1964-1973(.8)$ & $1990-1999(-.74)$ & 1950 - $1959(1.17)$ & $1990-1999(-.98)$ \\
\hline Gfdl-cm2.1 & & & $1955-1964(.6)$ & $1968-1999(-1.5)$ & $1965-1974(1.1)$ & $1985-1994(-1.1)$ \\
\hline
\end{tabular}

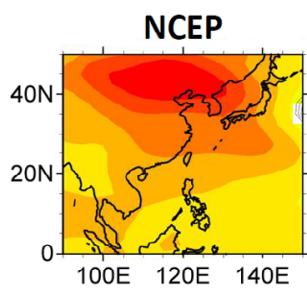

GISS-AOM

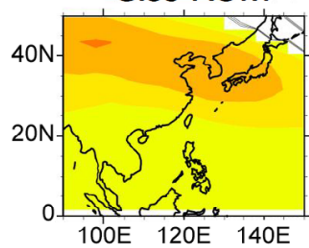

IPSL-CM4
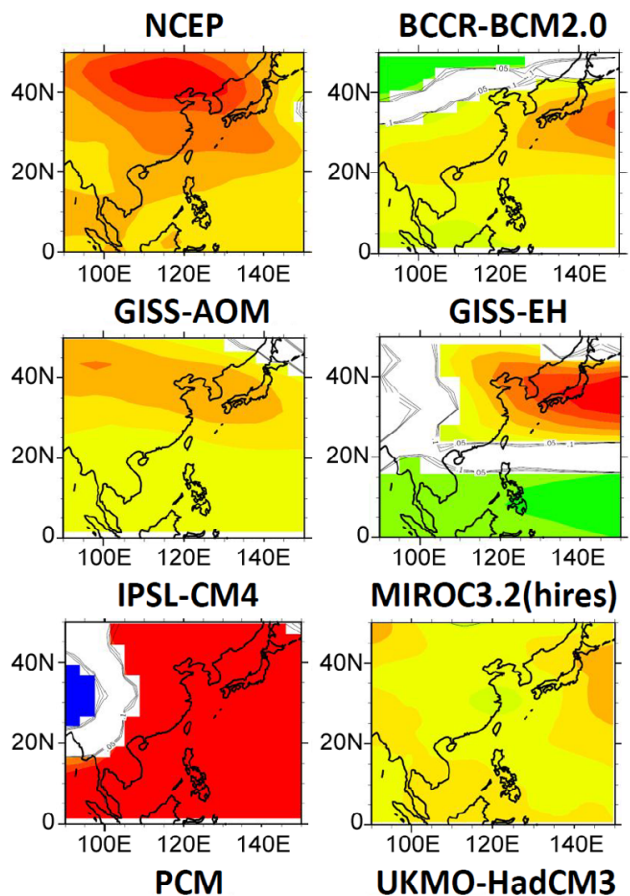

GISS-EH

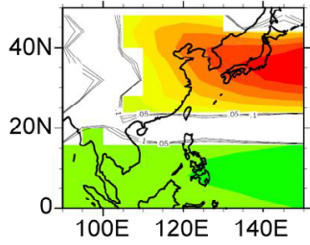

MIROC3.2(hires)

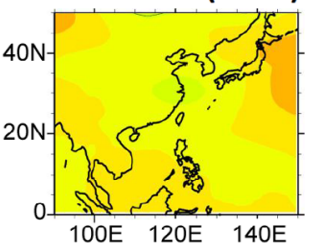

UKMO-HadCM3
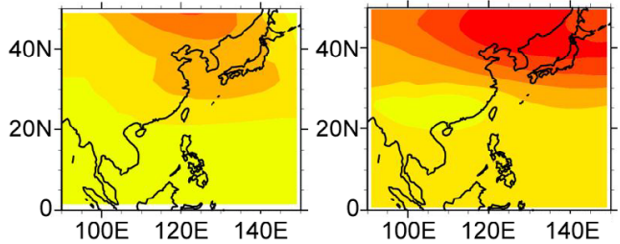

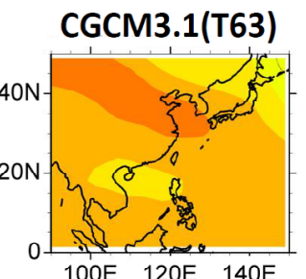

GISS-ER

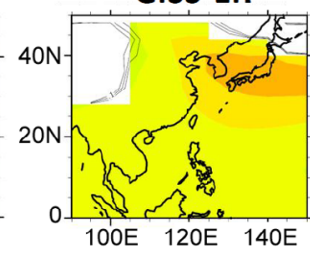

MIROC3.2(medres)
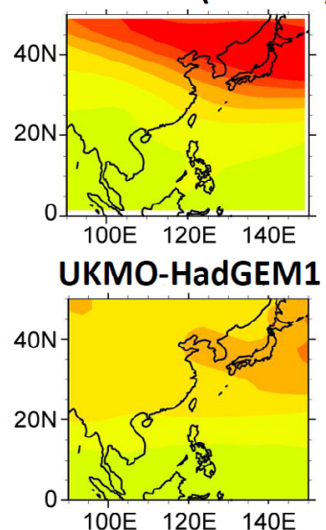

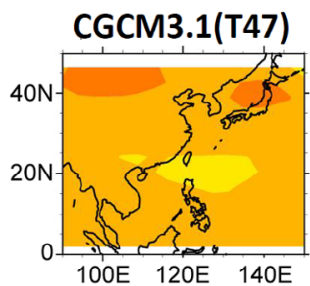

INM-CM3.0
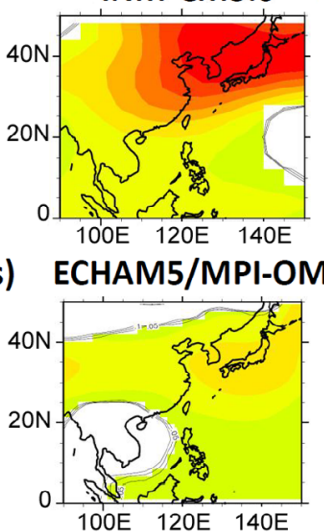

CNRM-CM3

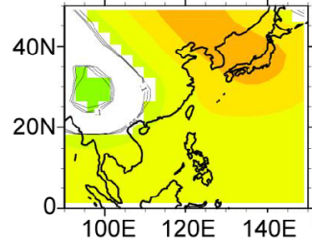

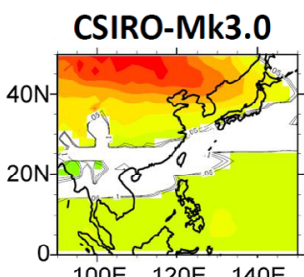

100E 120E 140E INGV-SXG

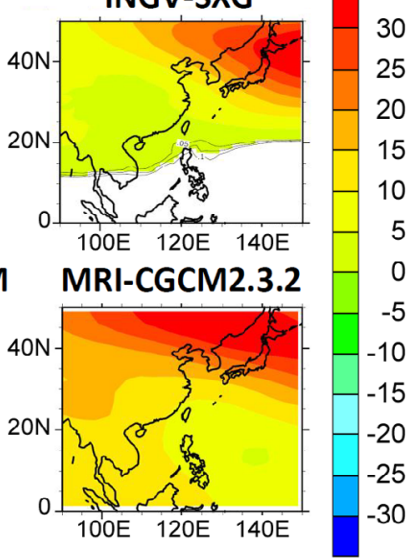

Fig. 8. Decadal difference between the negative and positive monsoon decades for 500 hpa geopotential height. 

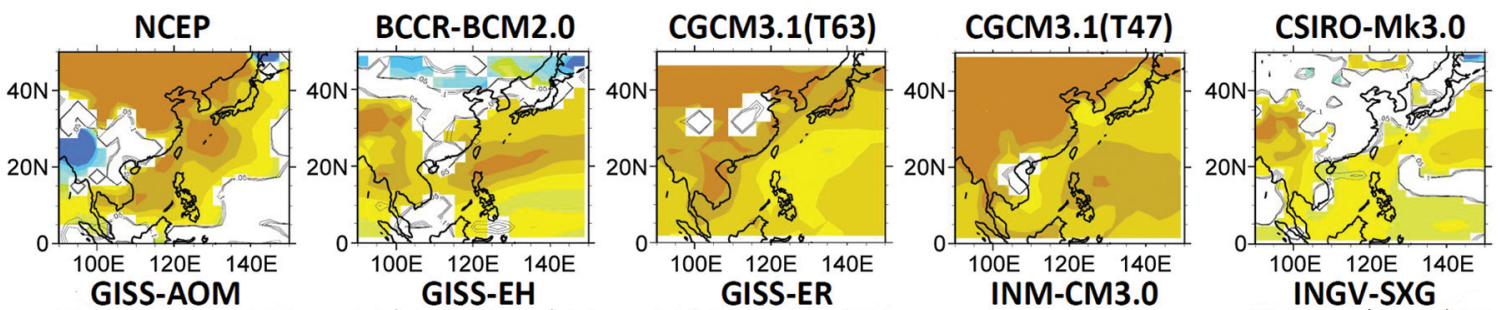

\section{$\operatorname{deg} C$}
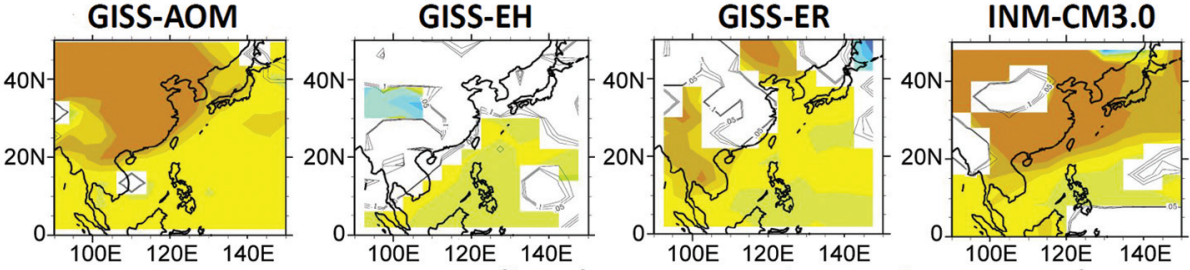

INGV-SXG

IPSL-CM4
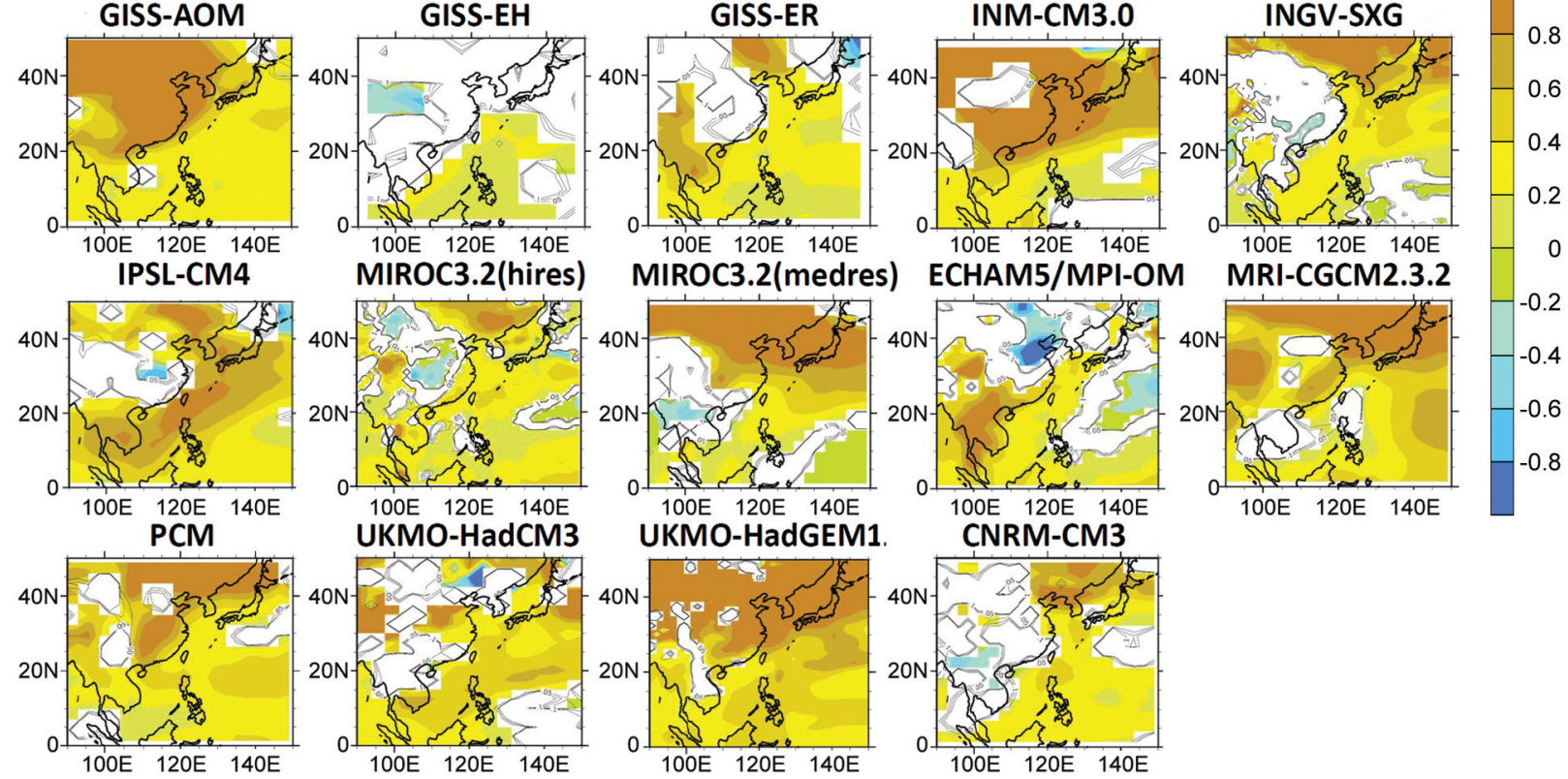

Fig. 9. Decadal difference between the negative and positive monsoon decades for surface air temperature.
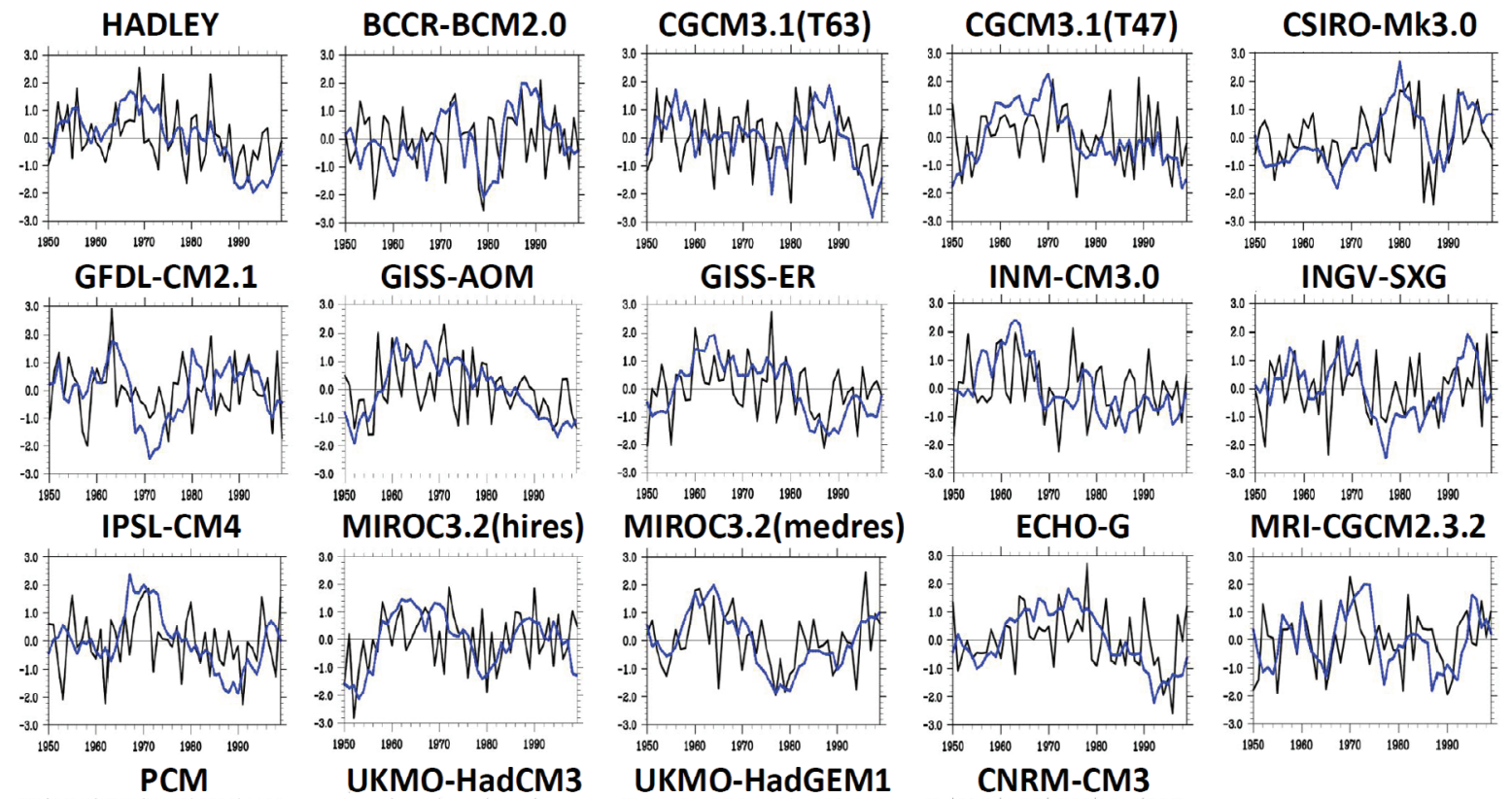

GISS-ER

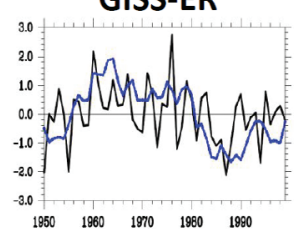

INM-CM3.0

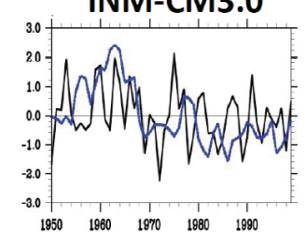

MIROC3.2(hires)
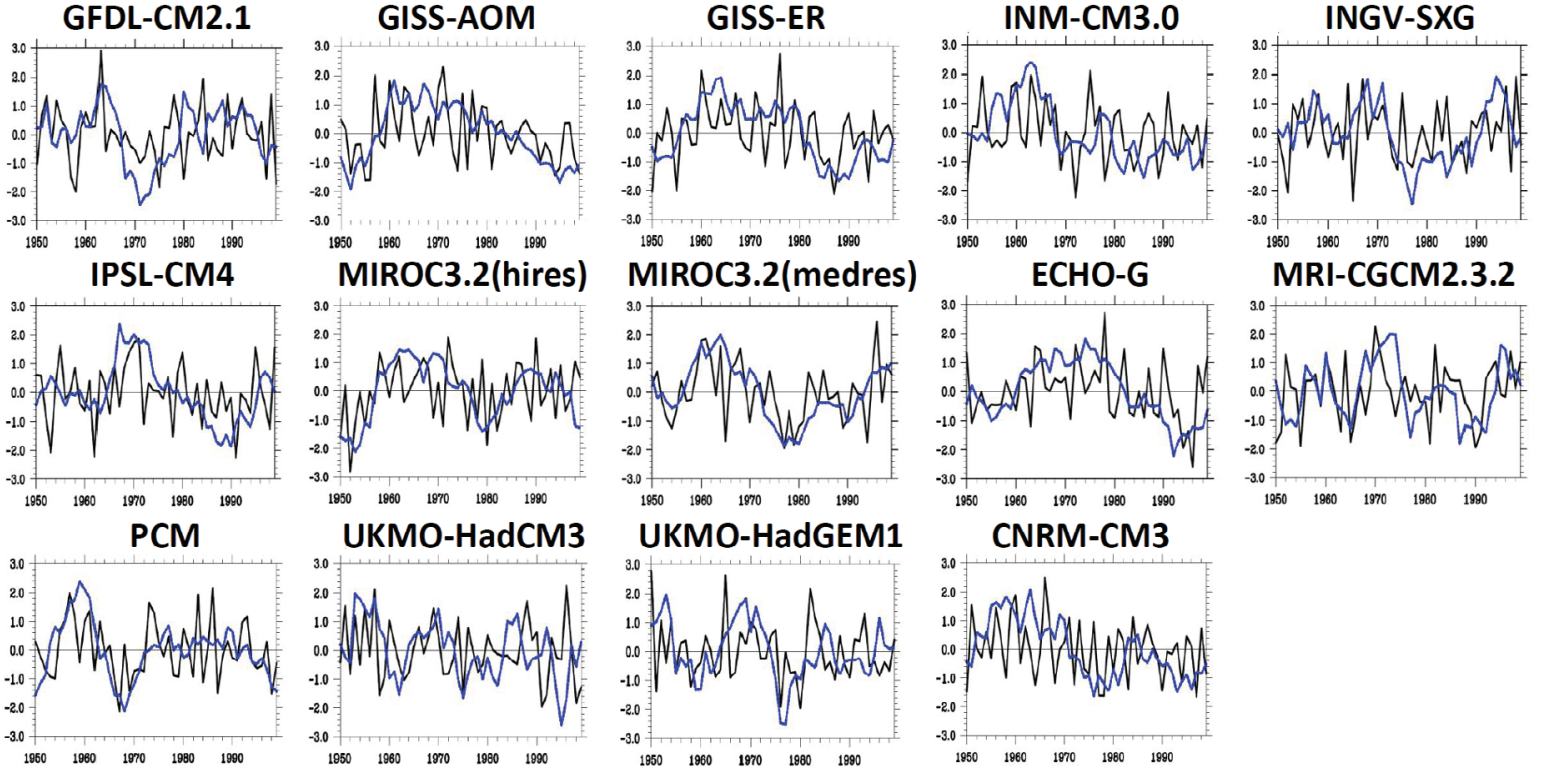

Fig. 10. Time series of IGONGDY for GCMs showing weakening of EAWM and observation (black line shows the inter-annual component and blue line shows the decadal component of monsoon index in each figure). 

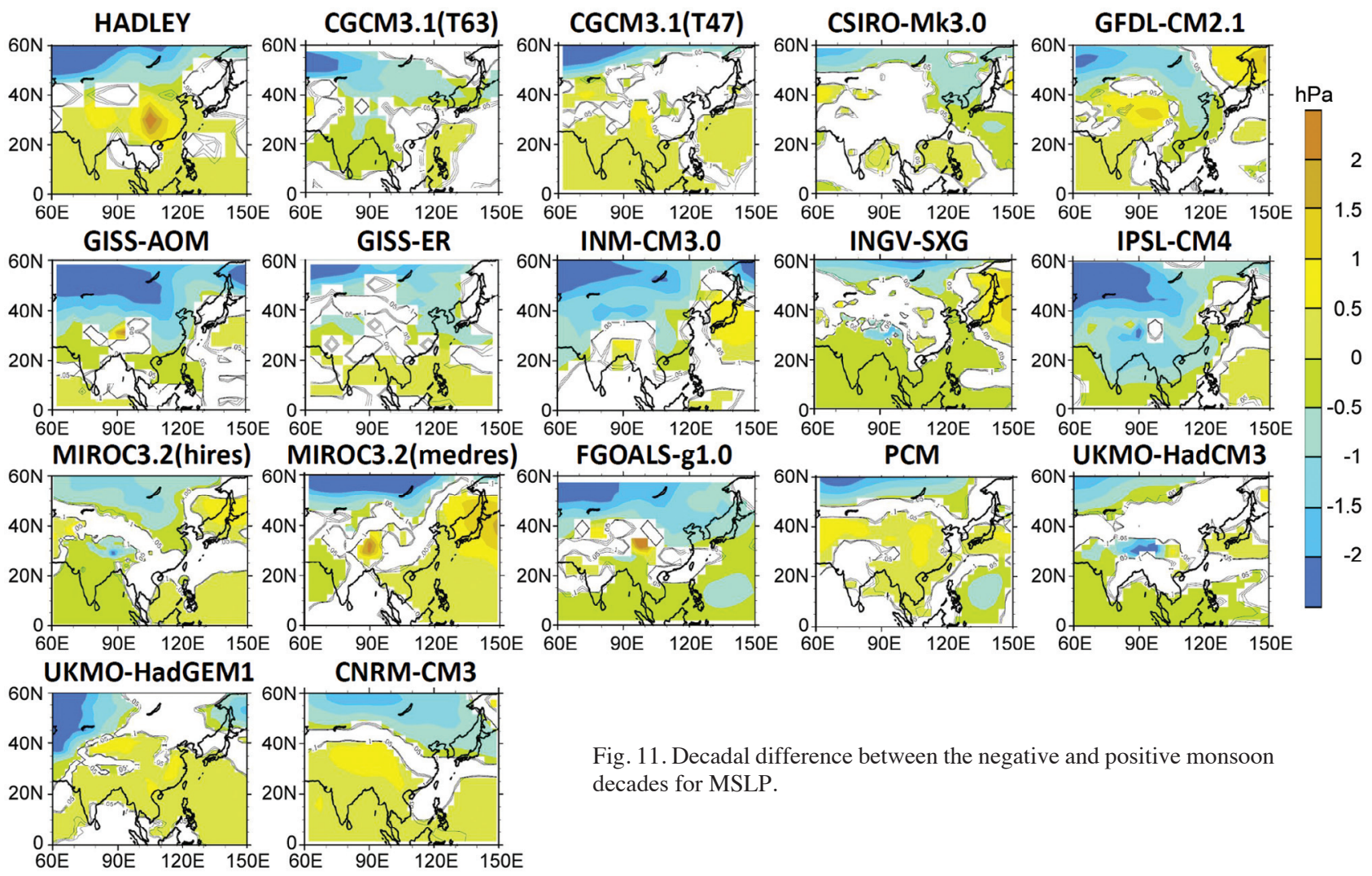

Fig. 11. Decadal difference between the negative and positive monsoon decades for MSLP.

simulations(Table 4, column 12). The composite difference in observed temperature indicates that positive monsoon phase is characterized by a significant rise of temperature over China, Japan, Korea, and Taiwan (not shown). This feature is exhibited by CGCM3.1(T63), CSIRO-Mk3.0, GFDL-CM2.1,GFDL-CM2.0,GISS-AOM,GISS-ER, INMCM3.0, MIROC3.2(medres), MRI-CGCM2.3.2, UKMOHadGEM1, CNRM-CM3 (Table 4, columns 13, 14).

Another index also illustrated here is ICHENW, which is associated with low level meridional wind component. The observed ICHENW index shows a clear weakening trend from 1980 with a switching of positive to negative monsoon phase in the late 1980s. It is interesting to note that the two previous indices show two weakening signs in the time series, the first one occurs in the late 1960s which shows a gradual weakening and the second one occurs in the late 1980s which shows a sharp change from positive to negative. The weakening northeasterly that occurred in the late 1980s coincides with the second weakening. The reasons for this are not clear. It is conjecture that the ICHENW reflects the northeasterly in the subtropical East Asia, i.e., in the lower latitudes than the previous two indices. The weakening of EAWM occurred earlier in higher latitudes and started later in the subtropical region when a more significant weakening occurred in a much larger area. Some GCMs like BCCR-BCM2.0, CGCM3.1(T63), CGCM3.1(T47), GISS-AOM, GISS-ER, INM-CM3.0,
IPSL-CM4, MIROC3.2(hires), ECHAM5/MPI-OM, PCM exhibit this weakening feature clearly (Fig. 12). However, the transition period as well as the positive and negative monsoon decades varies in case of different GCMs with respect to observation (Table 5). The GCMs having pronounced strong/weak monsoon are considered only for further study (Table 5). The composite difference between negative and positive monsoon for observed temperature characterizes negative monsoon with significant rise of temperature over north China, Korea, Japan, Taiwan and significant weakening of the Siberian High, which is pronounced in GCMs like INM-CM3.0, IPSL-CM4, UKMO-HadCM3, with reasonable spatial pattern correlations (Table 4, column 20). The weaker northerly and northeasterly are simulated for the low-level wind component ( $925 \mathrm{hPa}$ ) in negative monsoon phase is another distinctive feature in the observed data (Fig. 13) and is simulated by some GCMs, including BCCR-BCM2.0, INM-CM3.0, IPSL-CM4, MIROC3.2(hires), MIROC3.2(medres), CNRM-CM3 (Table 4, column 19), with reasonable spatial correlations for the $925 \mathrm{hPa}$ stream function for some of the GCMs (Table 4, column 18).

\section{CONSTRUCTION OF A MONSOON MATRIX}

Here we assess the capability of the CMIP3 models to simulate the EAM variability. Because a large number of variables show a diverse number of outcomes, we develop 

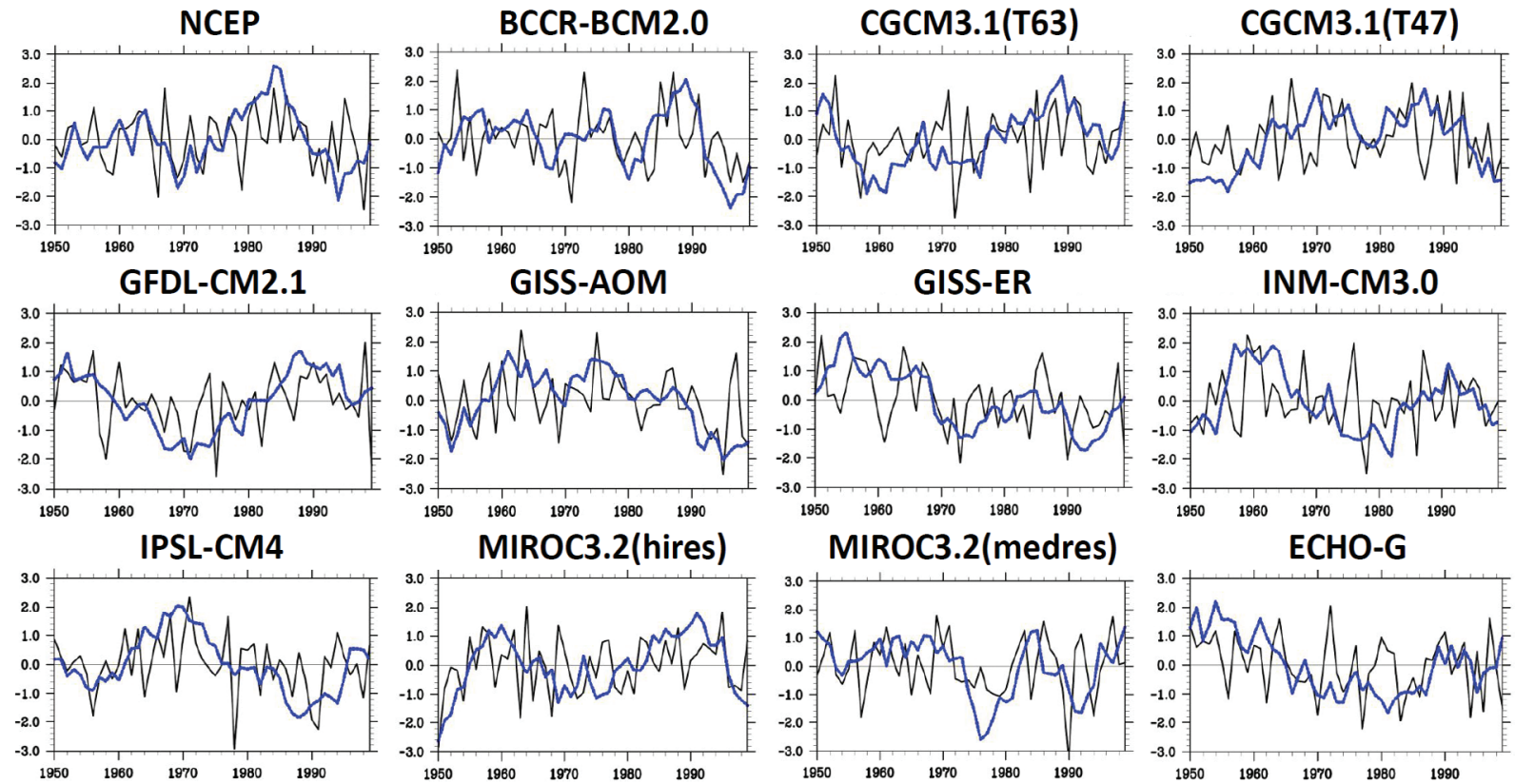

MIROC3.2(hires)

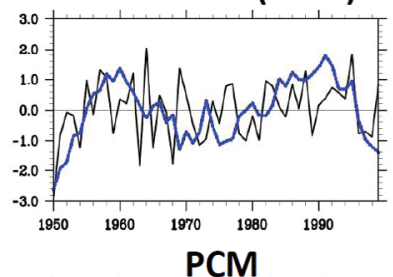

MIROC3.2(medres)
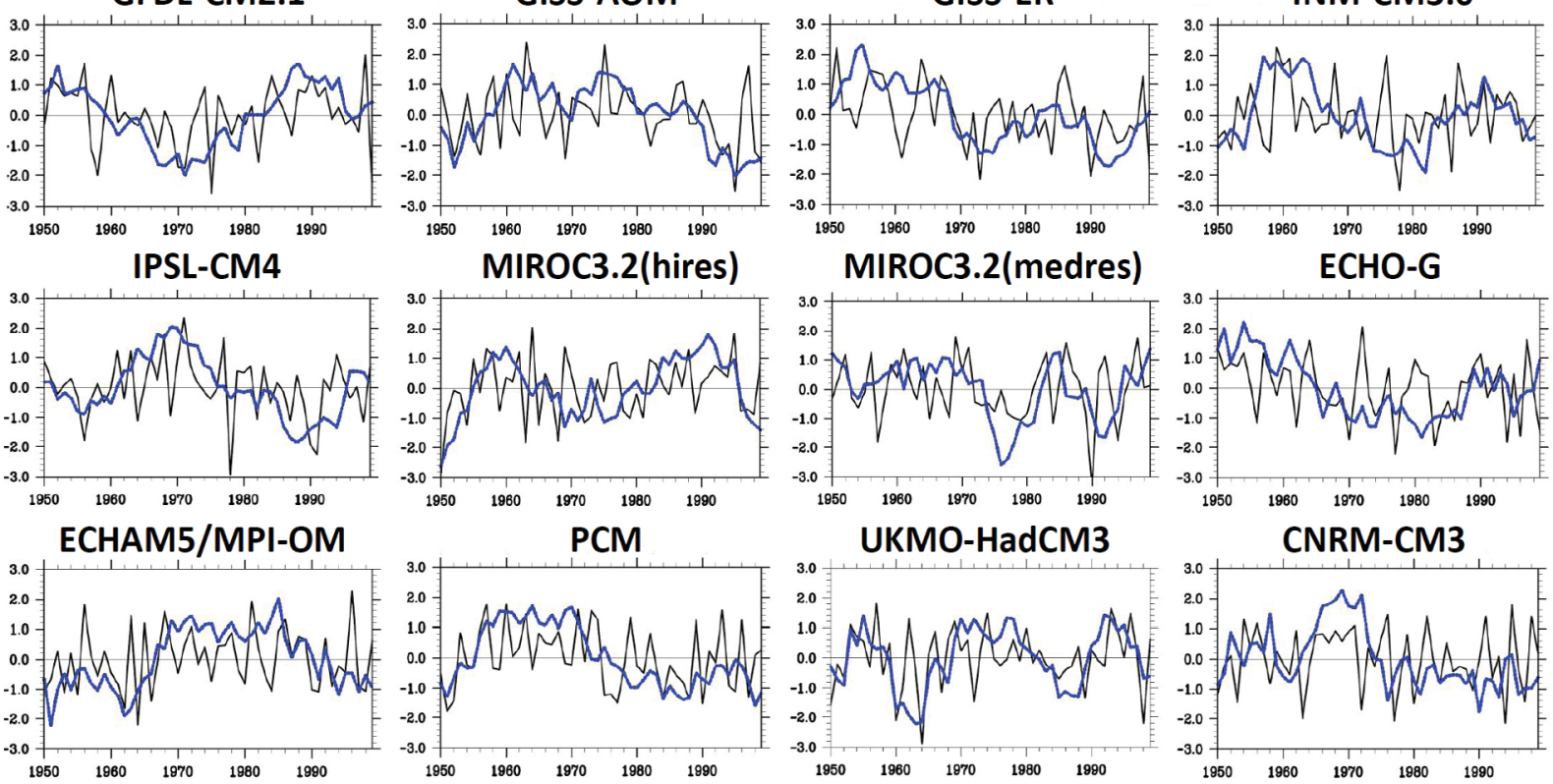

Fig. 12. Time series of ICHENW of GCMs showing weakening and observation(black line shows the inter-annual component and blue line shows the decadal component of monsoon index in each figure).
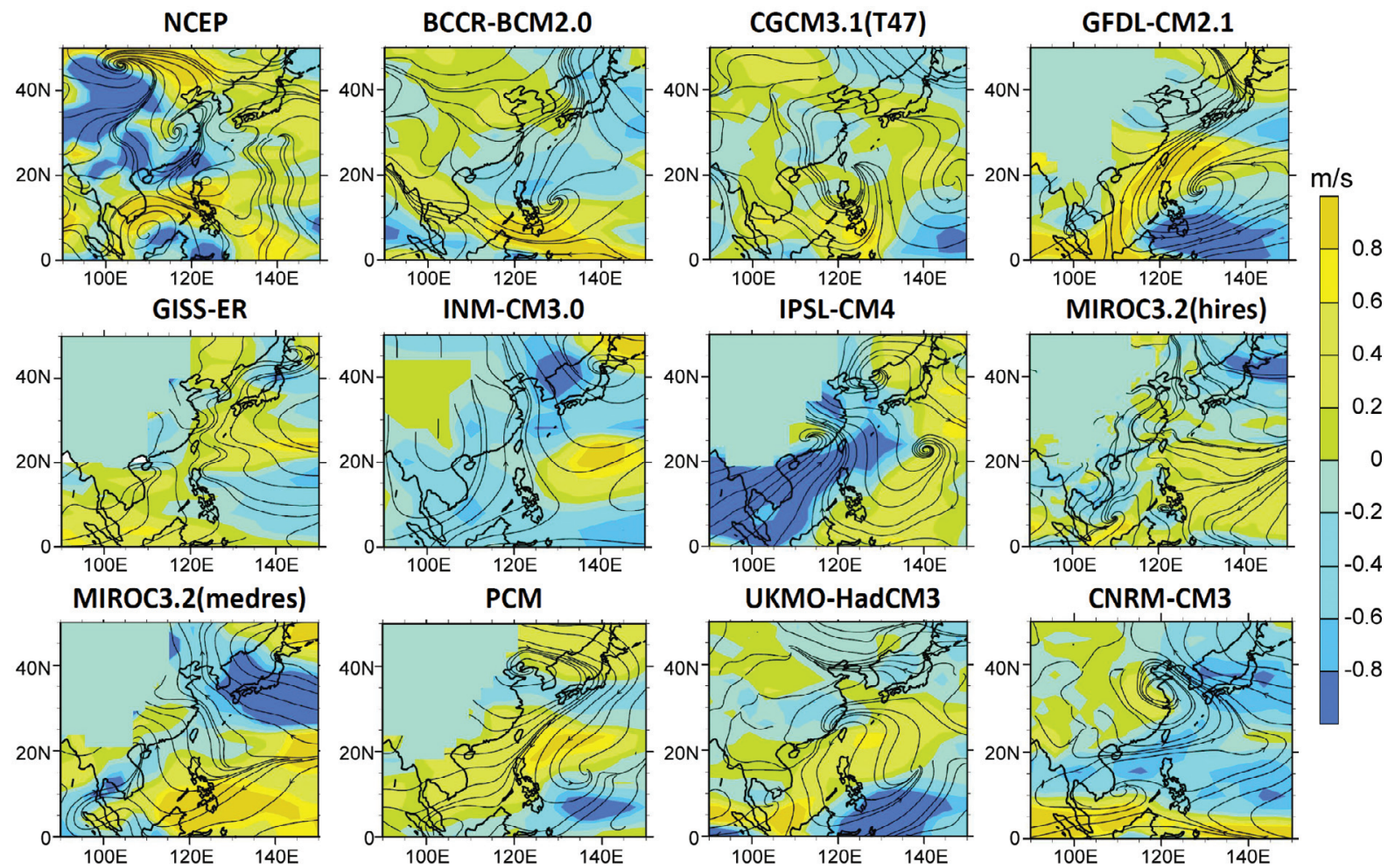

Fig. 13. Decadal difference between the negative and positive monsoon decades for stream function at $925 \mathrm{hPa}$. 
two robust matrices simultaneously for summer and winter (Tables 3,4$)$ that summarize model performance in a concise way. The sizes of the matrices are $24 \times 11$ and $24 \times$ 21 for summer and winter, respectively with the 24 GCMs in rows and other variables in columns. These matrices are expanded to study both qualitative and quantitative aspects to compare model outputs with the observed data. Qualitatively the distinctive features of East Asian monsoon system which separates the positive and negative phases are compared with observation. Moreover, in case of quantitative assessment, these matrices will restrict to scalar measure. Pattern correlation coefficient is a popular statistical measure consistent with this definition.

The matrices demonstrate a considerable spreading of relative ranking of GCMs from one variable to another after analyzing the individual variables. However, based on the relative performance of all the fields considered, some models show better results than others. The quantitative component of summer monsoon matrix indicates that most of CMIP3 GCMs fail to properly simulate the summer monsoon variability. The information provided for the winter monsoon variability in winter monsoon matrix (Table 4) illustrates the relative performance of the GCMs. The CGCM3.1(T63), GISS-AOM, INGV-SXG, INM-CM3.0, MIROC3.2(medres), MRI-CGCM2.3.2,UKMO-HadCM3,UKMO-HadGEM1, and CNRM-CM3 exhibit clear superiority among the 24 models in simulating the EAWM variability. This conclusion is robust across the winter monsoon indices and the variables and the components considered here.

\section{CONCLUSION}

The aim of this study is to assess the relative merits of CMIP3 GCMs in simulating the inter-annual and interdecadal variability of the East Asian winter and summer monsoon. Simulations from twenty-four GCMs provided by CMIP3 are compared with the observed data according to space and time structure.

The summer monsoon is quantified by two competent indices, the Wang-Fan index and tripole rainfall pattern. The Wang-Fan index is mainly analyzed in decadal time scale. Some GCMs, such as GISS-EH, GISS-ER, MRI-CGCM2.3.2, UKMO-HadGEM1, CSIRO-Mk3.0, IPSL-CM4, and CCSM3 show a clear weakening in later part of 50 years (1950 - 1999) like observation, although the transition time differs. The spatial analysis shows that the negative phase exhibits higher rainfall over southern China, Taiwan and northern China, making central China dry. This feature is clearly associated with the anti-cyclonic circulation of wind anomaly over the Western North Pacific. These GCMs are more accurate in simulating large-scale circulation anomaly than rainfall anomaly. A better simulation in circulation does not warrant a similar result for rainfall. On the other hand, GCMs lacking circulation simulation skill do not produce skillful rainfall simulation. This rainfall feature is evident in both inter-annual and inter-decadal component of the tripole pattern. The positive and negative anomalies are elongated in the east-west direction and are relatively narrow in meridional direction for both components. Corresponding time series shows a distinct widening of amplitude of inter-annual variability in two recent decades which is only exhibited by GCMs like GISS-EH. CSIRO-Mk3.0, CSIROMk3.5, GFDL-CM2.0, GFDL-CM2.1, GISS-AOM, GISSEH, INM-CM3.0, FGOALS-g1 .0, INGV-SXG, MIROC3.2(hires), MIROC3.2(medres), PCM, UKMO-HadCM3, UKMO-HadGEM1 showing distinct tripole pattern in first or second EOF of their inter-annual variability with reasonably well spatial pattern correlation. The temporal evolution of the EOF of tripole pattern associated with the inter-decadal variability exhibits also the switching of phase. CSIROMk3.0, MRI-CGCM2.3.2, UKMO-HadGEM1 has better performance than rest of the GCMs in simulating the summer monsoon variability.

Three winter monsoon indices, reflecting distinctive features regulating the variability of East Asian winter monsoon, are chosen for this analysis. ISUNBM is associated with 500-hpa East Asian trough, IGONGDY is associated east-west pressure contrast and ICHENW is associated with subtropical surface meridional wind. Temporal analysis of observed data reveals the decreasing trend of these three monsoon indices, clearly indicates the sharp weakening of winter monsoon after 1980s with a switching of phase in mid-80s. This feature in ISUNBM is exhibited by some of the GCMs like GISS-AOM, INM-CM3.0, IPSL-CM4, MRICGCM2.3.2, PCM, UKMO-HadCM3, UKMO-HadGEM1, MIROC3.2(hires), MIROC3.2(medres), CNRM-CM3, BCCR-BCM2.0, CGCM3.1(T47), CGCM3.1(T63), GISS-ER, CSIRO-Mk3.0, GISS-EH, INGV-SXG, ECHAM5/MPIOM. In case of IGONGDY, BCCR-BCM2.0, CGCM3.1(T63), CGCM3.1(T47), CSIRO-Mk3.0, GFDL-cm2.1, GISSAOM, GISS-ER, INGV-SXG, INM-CM3.0, IPSL-CM4, MIROC3.2(hires), MIROC3.2(medres), MRI-CGCM2.3.2, ECHO-G, PCM, UKMO-HadCM3, UKMO-HadGEM1, CNRM-CM3 do a reasonable job. Furthermore, BCCRBCM2.0, CGCM3.1(T63), CGCM3.1(T47),CNRM-CM3, UKMO-HadCM3, GISS-AOM, GISS-ER, INM-CM3.0, IPSL-CM4, MIROC3.2(hires), MIROC3.2(medres), ECHOG, ECHAM5/MPI-OM, PCM, UKMO-HadGEM1 simulate a weakening trend of ICHENW. The spatial analysis of observed data reveals that the negative phases of all the three indices are associated with weakening of Siberian High and rise temperature over China, Korea, Japan, Taiwan. These features are well defined by some GCMs like CGCM3.1(T63), GISS-AOM, INGV-SXG, INM-CM3.0, MIROC3.2(medres), MRI-CGCM2.3.2, UKMO-HadCM3, UKMO-HadGEM1, and CNRM-CM3.

Two monsoon matrices based on both qualitative and quantitative assessment are constructed for the summer and 
winter monsoon. The constructed matrices provide a concise and complete representation of relative merits of CMIP3 GCMs in simulating the East Asian Monsoon Variability. The summer monsoon matrix shows a complicated result. Although some of the GCMs like, CSIRO-Mk3.0, MRICGCM2.3.2, UKMO-hadGEM1 show better performance than other in most of aspect still they are poor in few aspect also. Based on this result, it is difficult to choose any GCM with good performance in every aspect. This kind of situation is not surprising considering the complicated variability of the EASM involving convection, which is one of the major deficiencies of the current GCMs. On the contrary, the winter monsoon matrix provides a clear picture about the relative performances of the GCMs. The qualitative and quantitative assessment shows very good performance of CGCM3.1(T63), GISS-AOM, INGV-SXG, INM-CM3.0, MIROC3.2(medres), MRI-CGCM2.3.2, UKMO-HadCM3, UKMO-HadGEM1, and CNRM-CM3 almost in every respect.

Acknowledgements The authors thank the National Centre for Disaster Research and National Science Council of Taiwan, Republic of China, for support in research grants NSC 98-2625-M-492-011, NSC 98-2625-M-492-001 and NSC 98-211-M-002-013-MY3 on studying climate change over East Asia.

\section{REFERENCES}

Annamalai, H., K, Hamilton, and K. R. Sperber, 2007: The South Asian summer monsoon and its relationship with ENSO in the IPCC AR4 simulations. J. Climate, 20, 1071-1092, doi: 10.1175/JCLI4035.1. [Link]

Basnett, T. and D. Parker, 1997: Development of Global Mean Sea Level Pressure Data Set GMSLP2: Climate Research Technical Note, 79, Hadley Centre Met Office.

Chang, C. P., Z. Wang, and H. Endon, 2006: Asian winter monsoon. In: Wang, B. (Ed.), The Asian Monsoon, Springer Press, 89-127.

Chen, W., H. F. Graf, and R. Huang, 2000: The interannual variability of East Asian winter monsoon and its relation to the summer monsoon. Adv. Atmos. Sci., 17, 4660, doi: 10.1007/s00376-000-0042-5. [Link]

Cui, X. P. and Z. B. Sun, 1999: East Asian winter monsoon index and its variation analysis. J. Nanjing Inst. Meteorol., 22, 321-325.

Delworth, T. L. and T. R. Knutson, 2000: Simulation of early $20^{\text {th }}$ century global warming. Science, $\mathbf{2 8 7}, 2246-$ 2250, doi: 10.1126/science.287.5461.2246. [Link]

Giorgi, F. and R. Francisco, 2000: Uncertainties in regional climate change prediction: A regional analysis of ensemble simulations with the HADCM2 coupled AOGCM. Climate Dyn., 16, 169-182, doi: 10.1007/PL
00013733. [Link]

Gong, D. Y., S. W. Wang, and J. H. Zhu, 2001: East Asian winter monsoon and Arctic Oscillation. Geophys. Res. Lett., 28, 2073-2076, doi: 10.1029/2000GL012311. [Link]

Guo, Q. Y., 1994: Relationship between the variations of East Asian winter monsoon and temperature anomalies in China. J. Appl. Meteorol. Sci., 5, 218-225.

Hsu, H. H. and S. M. Lin, 2007: Asymmetry of the tripole rainfall pattern during the East Asian summer. J. Climate, 20, 4443-4458, doi: 10.1175/JCLI4246.1. [Link]

IPCC (Intergovernmental Panel on Climate Change), 2007: The Physical Basis, Contribution of Working Group I to the Fourth Assessment Report of the IPCC, Cambridge University Press, 996 pp.

Kalnay, E., M. Kanamitsu, R. Kistler, W. Collins, D. Deaven, L. Gandin, M. Iredell, S. Saha, G. White, J. Woollen, Y. Zhu, A. Leetmaa, R. Reynolds, M. Chelliah, W. Ebisuzaki, W. Higgins, J. Janowiak, K. C. Mo, C. Ropelewski, J. Wang, R. Jenne, and D. Joseph, 1996: The NCEP/NCAR 40-years reanalysis project. Bull. Amer. Meteorol. Soc., 77, 437-471, doi: 10.1175/15200477(1996)077<0437:TNYRP>2 .0.CO;2. [Link]

Kitoh, A. and T. Uchiyama, 2006: Changes in onset and withdrawal of the East Asian summer rainy season by multimodel global warming experiments. J. Meteorol. Soc. Jpn., 84, 247-258, doi: 10.2151/jmsj.84.247. [Link]

Kittel, T. G. F., F. Giorgi, and G. A. Meehl, 1998: Intercomparison of regional biases and doubled $\mathrm{CO}_{2}$-sensitivity of coupled atmosphere-ocean general circulation model experiments. Climate Dyn., 14, 1-15, doi: 10.1007/ s003820050204. [Link]

Kripalani, R. H., J. H. Oh, and H. S. Chaudhari, 2007: Response of the East Asian summer monsoon to doubled atmospheric $\mathrm{CO}_{2}$ : Coupled climate model simulations and projections under IPCC AR4. Theor. Appl. Climatol., 87, 1-28, doi: 10.1007/s00704-006-0238-4. [Link]

Lau, K. M., 1992: The East Asian summer monsoon rainfall variability and climate teleconnection. J. Meteorol. Soc. Jpn., 70, 211-241.

Lin, J. L., G. N. Kiladis, B. E. Mapes, K. M. Weickmann, K. R. Sperber, W. Lin, M. C. Wheeler, S. D. Schubert, A. D. Genio, L. J. Donner, S. Emori, J.-F. Gueremy, F. Hourdin, P. J. Rasch, E. Roeckner, and J. F. Scinocca, 2006: Tropical intraseasonal variability in 14 IPCC AR4 climate models. Part I: Convective signals. J. Climate, 19, 2665-2690, doi: 10.1175/JCLI3735.1. [Link]

Lin, J. L., K. M. Weickman, G. N. Kiladis, B. E. Mapes, S. D. Schubert, M. J. Suarez, J. T. Bacmeister, and M. I. Lee, 2008: Subseasonal variability associated with Asian summer monsoon simulated by 14 IPCC AR4 Coupled GCMs. J. Climate, 21, 4541-4567, doi: 10.11 75/2008JCLI1816.1. [Link] 
Lorenz,E.N., 1982: Atmospheric predictability experiments with a large numerical model. Tellus, 34, 505-513, doi: 10.1111/j.2153-3490.1982.tb01839.x. [Link]

Mitchell, T. D. and P. D. Jones, 2005: An improved method of constructing a database of monthly climate observations and associated high-resolution grids. Int. J. Climatol., 25, 693-712, doi: 10.1002/joc.1181. [Link]

Nitta, T., 1987: Convective activities in the tropical western Pacific and their impact on the northern hemisphere summer circulation. J. Meteorol. Soc. Jpn., 65, 373390 .

Nitta, T. and Z. Z. Hu, 1996: Summer climate variability in China and its association with 500-hPa height and tropical convection. J. Meteorol. Soc. Jpn., 74, 425445.

Raick, C., K. Soetaert, and M. Grégoire, 2006: Model complexity and performance: How far can we simplify? Prog. Oceanogr., 70, 27-57, doi: 10.1016/j.pocean.20 06.03.001. [Link]

Shi, N., 1996: Features of the East Asian winter monsoon intensity on multiple time scale in recent 40 years and their relation to climate. J. Appl.Meteorol.Sci., 7, 175182.

Sun, B. M. and C. Y. Li, 1997: Relationship between the disturbances of East Asian through and tropical convective activities in boreal winter. Chin. Sci. Bull., 42, 500-504. (in Chinese)

Visser, H., R. J. M. Folkert, J. Hoekstra, and J. J. de Wolff, 2000: Identifying key sources of uncertainty in climate change projections. Clim. Change, 45, 421-457, doi: 10.1023/A:1005516020996. [Link]

Wang, B. and Z. Fan, 1999: Choice of South Asian Summer monsoon indices. Bull. Amer. Meteorol. Soc., 80, 629638, doi: 10.1175/1520-0477(1999)080<0629:COSAS $\mathrm{M}>2.0 . \mathrm{CO} ; 2 .[\underline{\mathrm{Link}}]$

Wang, B., Z. Wu, J. Li, J. Liu, C. P. Chang, Y. Ding, and G. Wu, 2008a: How to measure the strength of the East Asian summer monsoon? J. Climate, 21, 4449-4463, doi: 10.1175/2008JCLI2183.1. [Link]
Wang, L. and W. Chen, 2010: How well do existing indices measure the strength of the East Asian winter monsoon? Adv. Atmos. Sci., 27, 855-870, doi: 10.1007/s0 0376-009-9094-3. [Link]

Wang, L., W. Chen, and R. Huang, 2008b: Interdecadal modulation of PDO on the impact of ENSO on the East Asian winter monsoon. Geophys. Res. Lett., 35, L20702, doi: 10.1029/2008GL035287. [Link]

Wang, L., W. Chen, W. Zhou, and R. Huang, 2009a: Interannual variations of East Asian trough axis at $500 \mathrm{hPa}$ and its association with the East Asian winter monsoon pathway. J. Climate, 22, 600-614, doi: 10.1175/2008JCLI2295.1. [Link]

Wang, L., R. Huang, L. Gu, W. Chen, and L. Kang, 2009b: Interdecadal variations of East Asian winter monsoon and their association with quasi-stationary planetary wave activity. J. Climate, 22, 4860-4872, doi: 10.11 75/2009JCLI2973.1. [Link]

Webster, P. J. and S. Yang, 1992: Monsoon and ENSO: Selectively interactive systems. Q. J.R. Meteorol. Soc., 118, 877-926, doi: 10.1002/qj.49711850705. [Link]

Whetton, P. H., M. H. England, S. P. O'Farrell, I. G. Watterson, and A. B. Pittock, 1995: Global comparison of the regional rainfall results of enhanced greenhouse coupled and mixed layer ocean experiments: Implications for climate change scenario development. Clim. Change, 33, 497-519, doi: 10.1007/BF00141702. [Link]

Yu, R., B. Wang, and T. Zhou, 2004: Tropospheric cooling and summer monsoon weakening trend over East Asia. Geophys. Res. Lett., 31, L22212, doi: 10.1029/ 2004GL021270. [Link]

Zhang, X., J. Li, J. Yan, and Y. Ding, 2002: A study of circulation characteristics and index of South China Sea summer monsoon. Clim. Environ. Res., 7, 321-331, doi: 10.3878/j.issn.1006-9585.2002.03.05. [Link]

Zhou, T. and R. Yu, 2006: Twentieth-century surface air temperature over China and the globe simulated by coupled climate models. J. Climate, 19, 5843-5858, doi: 10.1175/JCLI3952.1. [Link] 